\title{
Minireviews
}

\section{Myalgic Encephalomyelitis/Chronic Fatigue Syndrome-Metabolic Disease or Disturbed Homeostasis due to Focal Inflammation in the Hypothalamus?}

\author{
Erifili Hatziagelaki, ${ }^{1}$ Maria Adamaki, ${ }^{1}$ Irene Tsilioni, George Dimitriadis, \\ and Theoharis $\mathrm{C}$. Theoharides
}

Second Department of Internal Medicine, Attikon General Hospital, Athens Medical School, Athens, Greece (E.H., M.A., G.D.); Laboratory of Molecular Immunopharmacology and Drug Discovery, Department of Immunology (I.T., T.C.T.) and Sackler School of Graduate Biomedical Sciences (T.C.T.), Tufts University School of Medicine, Boston, Massachusetts; and Departments of Internal Medicine and Psychiatry, Tufts University School of Medicine and Tufts Medical Center, Boston, Massachusetts (T.C.T.)

Received May 23, 2018; accepted August 1, 2018

\section{ABSTRACT}

Myalgic encephalomyelitis/chronic fatigue syndrome (ME/CFS) is a complex disease characterized by debilitating fatigue, lasting for at least 6 months, with associated malaise, headaches, sleep disturbance, and cognitive impairment, which severely impacts quality of life. A significant percentage of ME/CFS patients remain undiagnosed, mainly due to the complexity of the disease and the lack of reliable objective biomarkers. ME/CFS patients display decreased metabolism and the severity of symptoms appears to be directly correlated to the degree of metabolic reduction that may be unique to each individual patient. However, the precise pathogenesis is still unknown, preventing the development of effective treatments. The ME/CFS phenotype has been associated with abnormalities in energy metabolism, which are apparently due to mitochondrial dysfunction in the absence of mitochondrial diseases, resulting in reduced oxidative metabolism. Such mitochondria may be further contributing to the ME/CFS symptomatology by extracellular secretion of mitochondrial DNA, which could act as an innate pathogen and create an autoinflammatory state in the hypothalamus. We propose that stimulation of hypothalamic mast cells by environmental, neuroimmune, pathogenic and stress triggers activates microglia, leading to focal inflammation in the brain and disturbed homeostasis. This process could be targeted for the development of novel effective treatments.

\section{Introduction}

Myalgic encephalomyelitis/chronic fatigue syndrome (ME/ CFS) is defined by the original diagnostic criteria (Fukuda et al., 1994) and by the Canadian Consensus Criteria (Carruthers et al., 2003; Carruthers, 2007), followed by an international consensus (Carruthers et al., 2011) and newer clinical diagnostic criteria developed by a National Institutes of Health Pathways to Prevention Workshop (Haney et al., 2015) and the Institute of Medicine (Germain et al., 2017). $\mathrm{ME} / \mathrm{CFS}$ has also been known by other names (Unger et al.,

T.C.T. is the inventor of U.S. Patent Nos. 7,906,153 and 8,268,365 and PCT Application No. 13/722, 397 for the treatment of neuroinflammatory conditions.

The authors declare no conflict of interest.

Aspects of this work were funded in part by the Michael and Katherine Johnson Family Fund and an anonymous donation to T.C.T.

${ }^{1}$ E.H. and M.A. contributed equally to this work.

https://doi.org/10.1124/jpet.118.250845.
2016), most recently as systemic exertion intolerance disease (Monro and Puri, 2018).

$\mathrm{ME} / \mathrm{CFS}$ is a complex disease that involves the muscular, nervous, hormonal, and immune systems (Natelson, 2001; Georgiades et al., 2003; Brurberg et al., 2014; Brigden et al., 2017; Scheibenbogen et al., 2017). As the name implies, ME/CFS is characterized by debilitating fatigue lasting for at least 6 months, with severe impairment of daily functioning and associated symptoms, such as sleep disturbances, muscle aches, flu-like malaise, gastrointestinal symptoms, orthostatic intolerance, chronic or intermittent pain, as well as cognitive impairment reflected as memory and concentration difficulties (Natelson et al., 2007; Holgate et al., 2011; Yancey and Thomas, 2012; Ganiats, 2015; Komaroff, 2015; Scheibenbogen et al., 2017).

The intensity of symptoms appears to be significantly affected by exertion (Rowe et al., 2016). Anxiety and increased vulnerability to stress are also common in ME/CFS patients,

ABBREVIATIONS: acetyl-CoA, acetyl-coenzyme A; $\mathrm{CRH}$, corticotropin-releasing hormone; CSF, cerebrospinal fluid; FMS, fibromyalgia syndrome; HPA, hypothalamic-pituitary-adrenal; IL, interleukin; ME/CFS, myalgic encephalomyelitis/chronic fatigue syndrome; MetS, metabolic syndrome; mtDNA, mitochondrial DNA; SP, substance P; TCA, tricarboxylic acid; TNF, tumor necrosis factor. 
including children affected by the disease (Smith et al., 2003; Crawley et al., 2009). Abnormal hypothalamic-pituitary-adrenal (HPA) axis activity has been observed in many patients (Cleare et al., 2001), thus suggesting an association between $\mathrm{ME} / \mathrm{CFS}$ and disturbed neuro-endocrine mechanisms. Interestingly, ME/CFS patients are more likely to have migraine headaches than normal controls (Ravindran et al., 2011). ME/CFS is often comorbid with disorders (Table 1) that are characterized by central nervous system dysfunction (MartínezMartínez et al., 2014), and which are also negatively affected by stress (Theoharides and Cochrane, 2004; Theoharides, 2013): Gulf War illness (Gwini et al., 2016), pelvic pain syndrome/interstitial cystitis (Whitmore and Theoharides, 2011), fibromyalgia syndrome (FMS) (Theoharides et al., 2015c), and mastocytosis (Theoharides et al., 2015d) or mast cell activation syndrome (Akin, 2014; Petra et al., 2015). However, there are distinct differences between these other diseases, such as between ME/CFS and FMS (Abbi and Natelson, 2013; Pejovic et al., 2015).

$\mathrm{ME} / \mathrm{CFS}$ is estimated to affect as many as 2.5 million people in the United States, which corresponds to about $1 \%$ of the total U.S. population (Vincent et al., 2012; Ganiats, 2015; Komaroff, 2015). Other studies (Jason et al., 2009), including those conducted in Minnesota (Vincent et al., 2012), as well as in the United Kingdom (Nacul et al., 2011; Collin et al., 2017), Norway (Bakken et al., 2014), and Italy (Capelli et al., 2015), report a lower incidence. Women are apparently more susceptible than men, with an estimated ratio of 4:1 (Germain et al., 2017). The disease predominantly affects adults, even though symptoms may appear in childhood and adolescence (Jason et al., 2006; Nijhof et al., 2011; Crawley, 2014). Unfortunately, a significant number of suspected ME/CFS patients remain undiagnosed (Jason et al., 2006), mainly due to the complexity of the disease and the lack of reliable diagnostic biomarkers (Klimas et al., 2012). Multisystem diseases such as ME/CFS are often very timely and expensive to diagnose, and most patients go through years of searching and agony, as well as significant financial expenditures and impairment of their quality of life (Germain et al., 2017). The economic health burden for ME/CFS in the United States was estimated to be $\$ 24$ billion in 2018 (Jason et al., 2008). This makes imperative the need for the development of objective diagnostic biomarkers that will not only assist in the critical identification of patients with ME/CFS, but will also provide essential information on the pathophysiological mechanisms involved.

TABLE 1

Conditions often comorbid with ME/CFS

Condition

Chronic inflammatory response syndrome

Fibromyalgia syndrome

Ehlers-Danlos syndrome

Gulf War illness

Interstitial cystitis/bladder pain syndrome

Irritable bowel syndrome

Mast cell activation syndrome

Multiple chemical sensitivity syndrome

Post-Lyme syndrome

Postural orthostatic tachycardia syndrome

Post-traumatic stress disorder

Restless leg syndrome
A number of mechanisms and molecules (Table 2) have been implicated in the pathogenesis of ME/CFS (Gerwyn and Maes, 2017). Autoimmune (Sotzny et al., 2018) and metabolic (Tomas and Newton, 2018) pathways appear to play key roles in the pathophysiology of ME/CFS (Theoharides et al., 2004b; Maes et al., 2012b; Booth et al., 2012). Neuroimmune and neuroendocrine processes might also be involved, but are still largely unknown (Dietert and Dietert, 2008; Bower, 2012). Clinical and subclinical viral infections have been suspected, but never confirmed, as a possible risk factor for the development of ME/CFS (Frémont et al., 2009; Katz et al., 2009). The involvement of neuroinflammation of the brain has recently been suggested without any specific pathogenetic mechanism (Glassford, 2017; Morris et al., 2018; Tomas and Newton, 2018). Here, we give an overview of the current understanding of the associations between ME/CFS and metabolic disease, and propose that focal inflammation in the hypothalamus due to local activation of mast cells and microglia may alter homeostasis and provide a target for novel treatment approaches.

\section{Metabolic Irregularities}

$\mathrm{ME} / \mathrm{CFS}$ has been found to involve irregularities in metabolism, energy, amino acids, nucleotides, nitrogen, hormones, and oxidative stress (Armstrong et al., 2014; Germain et al., 2017). In particular, it has been proposed that the severe and prolonged fatigue experienced by ME/CFS patients may be a consequence of abnormalities in bioenergetic function (Tomas et al., 2017). Much evidence suggests that the pathophysiology of ME/CFS is highly associated with alterations in normal energy metabolic processes (Fluge et al., 2016) and abnormalities in cellular bioenergetics (Hornig et al., 2015; Fluge et al., 2016; Tomas et al., 2017). There is also evidence to suggest that patients with ME/CFS might be at an increased risk for developing metabolic syndrome-associated diseases, such as diabetes, cardiovascular disease, and thyroid disease (Maloney et al., 2009).

Apparently, systemic exertion intolerance in repeated cardiopulmonary exercise tests was demonstrated in ME/CFS patients compared with healthy controls, suggesting insufficient metabolic adaptation to incremental exercise (Keller et al., 2014; Vermeulen and Vermeulen van Eck, 2014). It should be noted that the Vermeulen and Vermeulen van Eck (2014) study

TABLE 2

Dysregulated molecules that may contribute to the pathogenesis of $\mathrm{ME} / \mathrm{CFS}$

Dysregulated Molecules that May Contribute to ME/CFS Pathogenesis

Cachexins
Calcineurin
Heavy metals
Herbicides
Inflammatory cytokines
Leptin
Melatonin
MicroRNAs
Mitochondrial enzymes
Neuroendocrine disruptors
Neuropeptides
Neurotransmitters
Reactive oxygen species
Toxins (mycotoxins, Borrelia toxins)
Uncoupling protein 2
Xenobiotics


included controls that were not matched to ME/CFS in terms of fitness, while the Keller et al. (2014) study had no controls. McCully and coworkers (McCully and Natelson, 1999; McCully et al., 2004) published a number of papers showing that when matched for aerobic fitness, cardiorespiratory responses to exercise in patients with ME/CFS only and ME/CFS plus FMS were not different from those in sedentary healthy controls (Cook et al., 2006).

Such intolerance, if real, may involve a switch to anaerobic glycolysis, i.e., a reduction in oxidative metabolism and an increase in lactate production (Murrough et al., 2010; Shungu et al., 2012), which constitute the most common metabolic alterations observed in patients with ME/CFS. These characteristics have mainly been attributed to deconditioning, a state characterized by loss of muscle tone and power from prolonged lack of use (Bains, 2008). However, even though increased lactate production was originally noted, possibly related to the reduction of postexercise oxygen delivery (McCully et al., 2004), the same effect could not be substantiated, suggesting a possible decrease in oxygen delivery perhaps due to reduced blood flow (McCully and Natelson, 1999). In particular, there was elevated ventricular lactate, but no significant difference in high-energy phosphatase metabolites in patients with ME/CFS compared with patients with major depressive disorder or healthy volunteers (Shungu et al., 2012). In some cases, alterations in glucose utilization and lactate production were evident only after physical exercise of ME/CFS patients (Fluge et al., 2016). $\mathrm{ME} / \mathrm{CFS}$ plasma and serum metabolomics point in the direction of a hypometabolic state (Fluge et al., 2016; Naviaux et al., 2016; Germain et al., 2017; Nagy-Szakal et al., 2018).

\section{ME/CFS Association with Metabolic Disease}

Metabolic syndrome (MetS) is a disorder characterized by an imbalance between energy expenditure and storage, and is diagnosed by the simultaneous presence of three of the following five conditions: 1) central type (or abdominal), 2) obesity, 3) increased blood pressure and elevated fasting glucose levels, 4) high levels of serum triglycerides, and 5) decreased high-density lipid cholesterol levels (Mottillo et al., 2010; Kaur, 2014). MetS is also linked to insulin resistance, a condition that can lead to hyperglycemia and the development of type 2 diabetes mellitus despite normal insulin secretion by pancreatic $\beta$-cells and hyperinsulinemia (Petersen and Shulman, 2006). In addition, high blood pressure and high cholesterol levels are closely linked to increased oxidative stress and endothelial dysfunction, thus enhancing the proinflammatory nature of microvascular atherosclerotic disease ( $\mathrm{Li}$ et al., 2007). In other words, subjects with MetS are at an increased risk of developing cardiovascular disease and type 2 diabetes mellitus (Isomaa et al., 2001; Dekker et al., 2005; Petersen and Shulman, 2006).

Approximately half of patients with ME/CFS also appear to have a previously undiagnosed medical condition, most often diabetes, cardiovascular disease, and thyroid diseases (Maloney et al., 2009). Few studies have investigated the possible associations between MetS and ME/CFS (Maloney et al., 2009; Naviaux et al., 2016; Germain et al., 2017; Bozzini et al., 2018). It was first suggested that patients with ME/CFS were twice as likely to have MetS compared with controls, after adjusting for body mass index, waist circumference, triglycerides, and glucose levels (Maloney et al., 2009). MetS components in the ME/CFS group were significantly correlated with worse fatigue, but not with worse physical or mental functioning, contrary to previous observations (Tsai et al., 2008; Maloney et al., 2009). A correlation of MetS with fatigue has also been observed in patients with FMS, a condition clinically similar to $\mathrm{ME} / \mathrm{CFS}$ in which muscle pain and fatigue are the main symptoms; specifically, MetS components (low-density lipoprotein cholesterol, as well as urinary norepinephrine/epinephrine and norepinephrine/cortisol ratios), were significantly higher in women with FMS compared with healthy controls (Loevinger et al., 2007).

Some studies have reported abnormal findings concerning the cardiovascular system-but one study was in patients with small hearts (Azevedo et al., 2007; Miwa and Fujita, 2009) and the other was in adolescents (Wyller et al., 2008) and autonomic nervous system dysfunction (Meeus et al., 2013). Low blood pressure was noted in certain ambulatory cases of patients with ME/CFS (Newton et al., 2009; Wyller et al., 2011; Frith et al., 2012). However, when patients with ME/CFS were matched to healthy controls by maximal oxygen consumption there were no differences in cardiovascular parameters (Cook et al., 2006).

Dysautonomia including postural orthostatic tachycardia syndrome may be present in many patients with ME/CFS (Hollingsworth et al., 2010) and could also explain other ME/CFS symptoms, such as fatigue, vertigo, decreased concentration, tremors, and nausea (Bozzini et al., 2018). Interestingly, the low systolic blood pressure observed in ME/CFS patients is usually accompanied by exaggerated diurnal variation, which is inversely correlated with increasing fatigue (Davis et al., 2000; Newton et al., 2009).

Overall, it appears that metabolic disease components show significant correlations with the fatigue in ME/CFS patients and not with the disease itself. For example, blood pressure, as well as insulin resistance, are probably secondary to fatigue, and most probably reflect the lack of physical activity and prolonged lack of muscle use in ME/CFS patients. This makes sense if one considers that low blood pressure could give rise to fatigue through brain or muscle hypoperfusion (Newton et al., 2009), and that insulin sensitivity is highly dependent on the oxidative capacity of the muscle (Cantó and Auwerx, 2009).

Metabolomics, small-molecule metabolite profiling (Daviss, 2005), has provided relevant information that could distinguish ME/CFS patients (Naviaux et al., 2016). Several studies have performed metabolite analysis of various biologic fluids [urine, blood, serum, and cerebrospinal fluid (CSF)] from ME/CFS patients (Georgiades et al., 2003; Jones et al., 2005; Niblett et al., 2007; Suárez et al., 2010; Armstrong et al., 2012, 2015; Hornig et al., 2016). However, despite confirming disturbances in energy, amino acid, nucleotide, nitrogen, hormone, and oxidative stress metabolomics, these studies have not been able to determine a distinct, reproducible metabolic profile for ME/CFS (Germain et al., 2017). Nevertheless, one study identified nine biochemical disturbances that were common to both male and female patients with ME/CFS, but not healthy controls (Naviaux et al., 2016). Overall, there were marked decreases in sphingolipid, glycosphingolipid, phospholipid, purine, microbiome aromatic amino acid, and branch chain amino acid metabolites, as well as in flavine adenine nucleotide and lathosterol, which identified the hypometabolic profile for ME/CFS. These changes correlated with disease severity and had an apparent diagnostic accuracy that exceeded $90 \%$ 
(Naviaux et al., 2016). Interestingly, the metabolic abnormalities found in ME/CFS patients were opposite (i.e., decreased instead of being increased) to those observed in MetS, suggesting that ME/CFS patients could be more resistant to hypertension, dyslipidaemia, obesity, and insulin resistance even though the previously studies discussed had reported an increased association between ME/CFS and MetS.

Another study that used targeted plasma metabolomics reported a similar trend of hypometabolic state in ME/CFS patients (Germain et al., 2017). Even though the metabolite compounds were not all identical to the ones studied by Naviaux et al. (2016), both studies agreed on the presence of disturbances in lipid and fatty acid metabolism (Germain et al., 2017). These findings are also in agreement with reported deficiencies in urea and tricarboxylic acid (TCA) cycles (ornithine/citrulline and pyruvate/isocitrate ratios), which ultimately result in reduced levels of ATP production in patients with ME/CFS (Yamano et al., 2016). Other studies revealed that ME/CFS patients have reduced substrates that enter oxidation downstream from pyruvate dehydrogenase, such as glutamine, glutamate, and phenylalanine, thus suggesting impaired pyruvate catabolism, which ultimately results in increased utilization of acetyl-coenzyme A (acetyl-CoA)producing amino acids as alternative substrates for fueling aerobic metabolism via the TCA cycle (Armstrong et al., 2012, 2015; Fluge et al., 2016). Reduced concentrations of amino acids that maintain TCA cycle capacity were detected in patients with ME/CFS (Fluge et al., 2016), suggesting impaired fueling of the TCA cycle by pyruvate. This finding is in line with the results of other studies where TCA cycle intermediates were also found to be reduced in both urine (Niblett et al., 2007) and plasma (Yamano et al., 2016) samples from ME/CFS patients.

\section{Mitochondrial Dysfunction}

Overall, the ME/CFS phenotype has been associated with mitochondrial dysfunction, AMP-activated protein kinase impairment, oxidative stress, and skeletal muscle cell acidosis (Kennedy et al., 2005; Myhill et al., 2009; Brown et al., 2015; Tomas et al., 2017). The main ME/CFS symptoms, such as fatigue, exercise intolerance, and myalgia, are also shared by patients diagnosed with primary mitochondrial disorders (Filler et al., 2014; Gorman et al., 2015). However, unlike the mitochondrial dysfunction observed in mitochondrial disorders, which is known to be caused by mutations in either nuclear or mitochondrial DNA (mtDNA) (Tomas et al., 2017), these mutations in patients with ME/CFS are extremely rare (Billing-Ross et al., 2016; Schoeman et al., 2017). In addition, certain mitochondrial enzymes have been found to discriminate between mitochondrial disorders and ME/CFS. Notably, respiratory chain complex I, III, and IV activity (Smits et al., 2011) appears to be significantly higher in ME/CFS patients. Instead, the ATP production rate was found to be within the normal range in ME/CFS patients, but significantly decreased in approximately three-quarters of the patients with mitochondrial disease, and was therefore regarded as the most reliable discrimination test (Smits et al., 2011).

Muscle biopsies from ME/CFS patients have shown mitochondrial degeneration, atrophy of type II fibers and fusion of mitochondrial cristae, decreased mitochondrial membrane permeability, severe deletions in mtDNA genes that are involved in cellular energy processes, as well as oxidative damage from increased production of free radicals (Myhill et al., 2009; Morris and Maes, 2013). Mitochondrial dysfunction has also been observed in peripheral mononuclear blood cells of ME/CFS patients, even though it has not yet been elucidated if they constitute the cause of the disease (Myhill et al., 2009, 2013; Tomas et al., 2017). Notably, a significant correlation has been observed between the extent of mitochondrial dysfunction and the degree of ME/CFS severity, thus suggesting that mitochondrial dysfunction might be a contributing factor in ME/CFS pathology, at least in a subset of patients (Myhill et al., 2009; Booth et al., 2012). However, it is difficult to assess mitochondrial dysfunction, which is usually done by measuring the levels of lactate and pyruvate in the serum; it is best done by serial serum sampling from an arm after a brief period of exercise.

When limited amounts of oxygen are available, as is usually the case with intense exercise, anaerobic glycolysis (otherwise called the lactic acid system) provides an effective means of energy production. During this process, glucose is catabolized via the glycolytic pathway, resulting in pyruvate being converted to lactate by lactate dehydrogenase. This process lasts 10-30 seconds during maximal effort and produces about 5\% of the glucose energy potential in the form of ATP molecules (two molecules of ATP for every molecule of glucose). ATP synthesis can be estimated by measuring the anaerobic threshold, i.e., the rate of oxygen consumption at work when blood lactic acid begins to accumulate and the maximal work rate (Morris and Maes, 2014). The anaerobic threshold indicates a switch during which ATP synthesis stops being produced by mitochondria and occurs via the anaerobic route (Morris and Maes, 2012), whereas anaerobic threshold and recovery time following exercise depend on lactate production and clearance rates (Fluge et al., 2016). When aerobic conditions are normal, pyruvate is transported into mitochondria and converted to acetyl-CoA by either pyruvate dehydrogenase or via degradation of fatty acids and ketogenic amino acids. In either case, acetyl-CoA is further oxidized in the TCA cycle, producing some ATP, and the electron transport chain (respiratory chain), which generates ATP from ADP by oxidative phosphorylation. AcetylCoA thereby serves to fuel mitochondrial respiration and ATP production by oxidative phosphorylation (Fluge et al., 2016) for essential tissue functions (Myhill et al., 2009).

Reduced ATP production is associated with increased levels of reactive oxygen species, which may ultimately lead to mitochondrial damage and the hypometabolic profile of ME/CFS (Armstrong et al., 2015; Naviaux et al., 2016). Severely reduced or impaired mitochondrial oxidative phosphorylation in ME/CFS patients is highly correlated with significantly increased intracellular lactate levels, even in the recovery phase of mild exercise where ATP synthesis is extremely low (Vermeulen et al., 2010; Morris and Maes, 2014).

Among the factors that may contribute to mitochondrial dysfunction, the most prominent ones appear to be increased levels of proinflammatory cytokines, such as interleukin (IL) $-1 \beta$ and tumor necrosis factor (TNF), which directly inhibit mitochondrial respiration by increasing mitochondrial membrane permeability, ultimately leading to membrane depolarization and increased production of reactive oxygen species (Morris and Maes, 2013). However, even though TNF is elevated in the serum of patients with FMS (Theoharides et al., 2010), it was not consistently elevated in ME/CFS 
(Brenu et al., 2011) but was apparently associated only with increased IL-4 (Hanson et al., 2001). There was also no significant difference in serum cytokine levels overnight (Nakamura et al., 2010) or postexercise (Nakamura et al., 2013). There is some evidence of a stronger correlation of cytokine alterations early in the course of illness rather than to severity (Hornig et al., 2015). It has been proposed that cytokine coexpression networks may be more predictive of ME/CFS phenotype (Klimas et al., 2012; Hornig et al., 2016), but looking for such biomarkers in the periphery would not reflect inflammation in the brain. One study reported that out of 27 cytokines studied in CSF from ME/CFS patients, only IL-10 was significantly reduced (Peterson et al., 2015). Another paper using network analysis of CSF cytokine levels reported an inverse relationship with IL-1 receptor antagonist only in classic, but not in atypical, ME/CFS (Hornig et al., 2017).

Certain microRNAs may turn out to be distinct or differentially expressed in ME/CFS. Recently, microRNAs have been implicated in the hypothalamic control of energy homeostasis (Najam et al., 2018). However, the available studies in patients with ME/CFS did not report any consistent pattern whether pre- or postexercise in plasma, (Brenu et al., 2014) natural killer cells (Petty et al., 2016), or CD8 ${ }^{+}$cells (Brenu et al., 2012). One recent important study showed exercise-induced changes in CSF fluid from patients with ME/CFS and Gulf War illness, and sedentary controls found 12 diminished microRNAs after exercise (Baraniuk and Shivapurkar, 2017, 2018).

\section{Focal Inflammation in the Diencephalon and Dysfunctional HPA Axis}

Neuroinflammation (Nakatomi et al., 2014; Glassford, 2017; Morris et al., 2018; Tomas and Newton, 2018) and immune dysfunction (Morris et al., 2014; Nijs et al., 2014; Trivedi et al., 2018) have been suggested as being involved in the pathogenesis of ME/CFS, but serum levels of proinflammatory cytokines have not been confirmed as will be discussed subsequently. Considerable evidence indicates that ME/CFS is characterized by dysfunction of the HPA axis (Theoharides et al., 2010;
Morris et al., 2017), and symptoms are known to worsen due to stress (Smith et al., 2003; Theoharides and Cochrane, 2004; Crawley et al., 2009; Theoharides, 2013). Stress can also worsen or precipitate obesity and cardiovascular events (Theoharides et al., 2008, 2011; Sismanopoulos et al., 2013; Alevizos et al., 2014) through local inflammation (Libby et al., 2002; Matusik et al., 2012).

Corticotropin-releasing hormone $(\mathrm{CRH})$ is secreted from the hypothalamus under stress and stimulates the HPA axis via activation of two main types of $\mathrm{G}$ protein-coupled receptors, CRHR-1 and CRHR-2 (Chrousos, 1995). CRH secreted under acute stress has been implicated in the pathophysiology of neuroinflammatory disorders and myocardial infarction (Jiang et al., 1996; Krantz et al., 2000; O’Kane et al., 2006; Slominski, 2009).

We propose that stimulation of hypothalamic mast cells by environment, neural, immune pathogenic (Lyme, mycotoxins), or stress triggers ( $\mathrm{CRH}$ and somatostatin) activates microglia leading to focal inflammation and disturbed homeostasis (Fig. 1). Mast cell and/or microglia triggers may derive from the nasal cavity, or may reach the brain area through a disrupted blood-brain barrier or through the lymphatics. Stimulated mast cells could secrete molecules that can alter homeostasis directly (via secretion of $\mathrm{CRH}$ and urocortin) or activate microglia (via secretion of histamine, tryptase, and mtDNA). Microglia then release more inflammatory molecules (IL-1 $\beta$, IL-6, and CCL2) that further disrupt homeostasis, cause mitochondrial dysfunction, and contribute to fatigue both centrally and peripherally. In fact, activated microglia molecules have been reported to contribute to the pathophysiology of sleep disorders (Nadjar et al., 2017). The involvement of more than one trigger can lead to a significantly heightened response and lower the triggering threshold of both mast cells and microglia, leading to chronic symptoms.

Mast cells are unique tissue immune cells involved in allergic reactions (Theoharides et al., 2015d); however, they also act as sensors of environmental and psychologic stress (Theoharides, 2017). Even though we invoke stimulation of mast cells in the hypothalamus, it does not necessarily mean

Hypothalamus

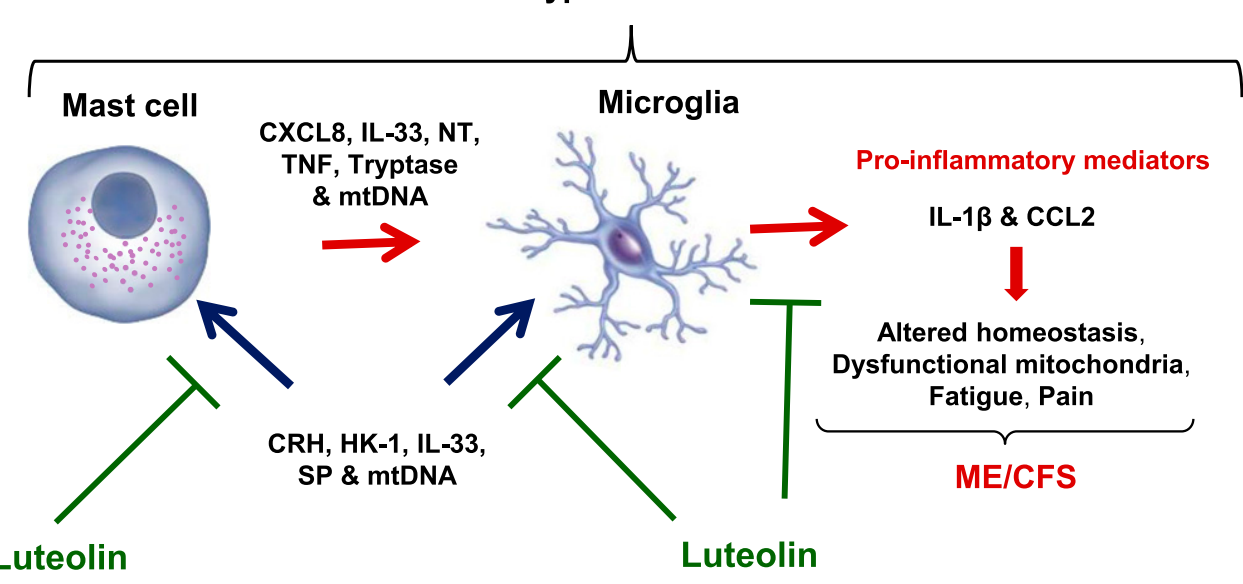

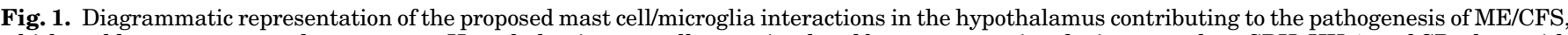

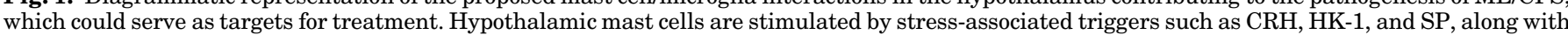

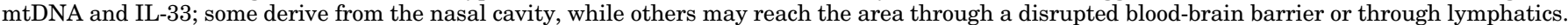

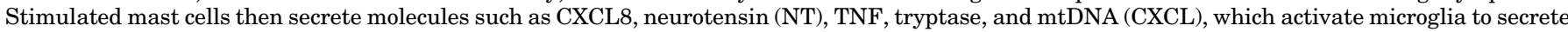

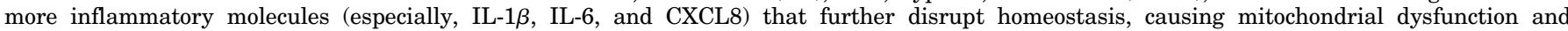
contributing to symptoms of ME/CFS. Luteolin could inhibit these processes at different steps, as shown. 
that mast cells should necessarily be stimulated outside the central nervous system. Nevertheless, there have been reports of an association between ME/CFS and acute rhinitis, including significantly higher TNF and CXCL8 levels in nasal lavage fluid (Repka-Ramirez et al., 2002). In addition, chronic rhinosinusitis symptoms were significantly higher in patients with ME/CFS (Chester, 2003), apparently due to nonallergic rhinitis (Baraniuk and Ho Le, 2007). It is well known that both allergic and perennial rhinitis involve activation of mast cells (Bachert et al., 2018). More recently, it was reported that the incidence of ME/CFS was higher in patients with a history of atopy (Yang et al., 2015). Moreover, circulating blood mast cell precursors were found to be higher in ME/CFS patients (Nguyen et al., 2017).

Mast cells are located perivascularly in the hypothalamus, thalamus, and third ventricle (Edvinsson et al., 1977; Pang et al., 1996). CRH could stimulate mast cells in the hypothalamus since the CRHR-1 gene is expressed on human cultured mast cells, activation of which induces production of vascular endothelial growth factor (Cao et al., 2005), which could increase permeability of the blood-brain barrier (Theoharides, 1990; Esposito et al., 2002; Theoharides and Konstantinidou, 2007) leading to inflammation of the brain (Theoharides et al., 2004a). Moreover, $\mathrm{CRH}$ is synthesized by mast cells (Kempuraj et al., 2004), implying it could have autocrine effects. Interestingly, even somatostatin stimulates mast cells (Theoharides et al., 1990). Mast cells are also found in the pineal, pituitary, and thyroid glands (Theoharides, 2017), further extending their contribution to the symptoms of ME/CFS, such as sleep disturbances, dysfunctional HPA axis, and fatigue due to thyroid dysfunction. Mast cells are well known for their role in allergic reactions (Beaven, 2009), but mast cells are now considered important in innate and acquired immunity (Galli et al., 2008), antigen presentation (Gong et al., 2010), and inflammation (Theoharides et al., 2012).

Mast cells can be stimulated by neurons, hormones, and environmental, neuroimmune, pathogenic, and stress triggers (Table 3) (Theoharides et al., 2015d; Theoharides, 2017). Reactive oxygen species can also stimulate mast cells (Swindle and Metcalfe, 2007; Robuffo et al., 2017; Toniato et al., 2017). Mast cells also secrete leptin, which could contribute to cachexia and fatigue (Taildeman et al., 2009). Mast cells secrete as many as 100 different mediators (Table 4) (Theoharides and Kalogeromitros, 2006; Wernersson and Pejler, 2014; Mukai et al., 2018), often selectively without degranulation (Theoharides et al., 2007) and utilizing different secretory pathways ( $\mathrm{Xu}$ et al., 2018). Mast cells can also secrete danger signals (Theoharides, 2016), including many chemokines and cytokines (Conti et al., 2017; Mukai et al., 2018), especially mtDNA (Zhang et al., 2012), which could act as an innate pathogen (Zhang et al., 2011), leading to a localized brain autoinflammatory response (Collins et al., 2004; Marques et al., 2012; Sun et al., 2013; Theoharides et al., 2013). Extracellular mtDNA could either be secreted directly in the diencephalon or could reach the brain through lymphatics (Louveau et al., 2015). We had reported that mtDNA is increased in the serum of children with autism spectrum disorder (Zhang et al., 2010). Mast cell-derived mediators can then stimulate microglia (Patel et al., 2016; Zhang et al., 2016) to secrete additional proinflammatory and homeostasisdisrupting molecules (Table 5), contributing to fatigue and neuropsychiatric symptoms (Theoharides et al., 2016). It is interesting that peptide $\mathrm{Y}$ was found to be elevated in plasma
TABLE 3

Mast cell triggers

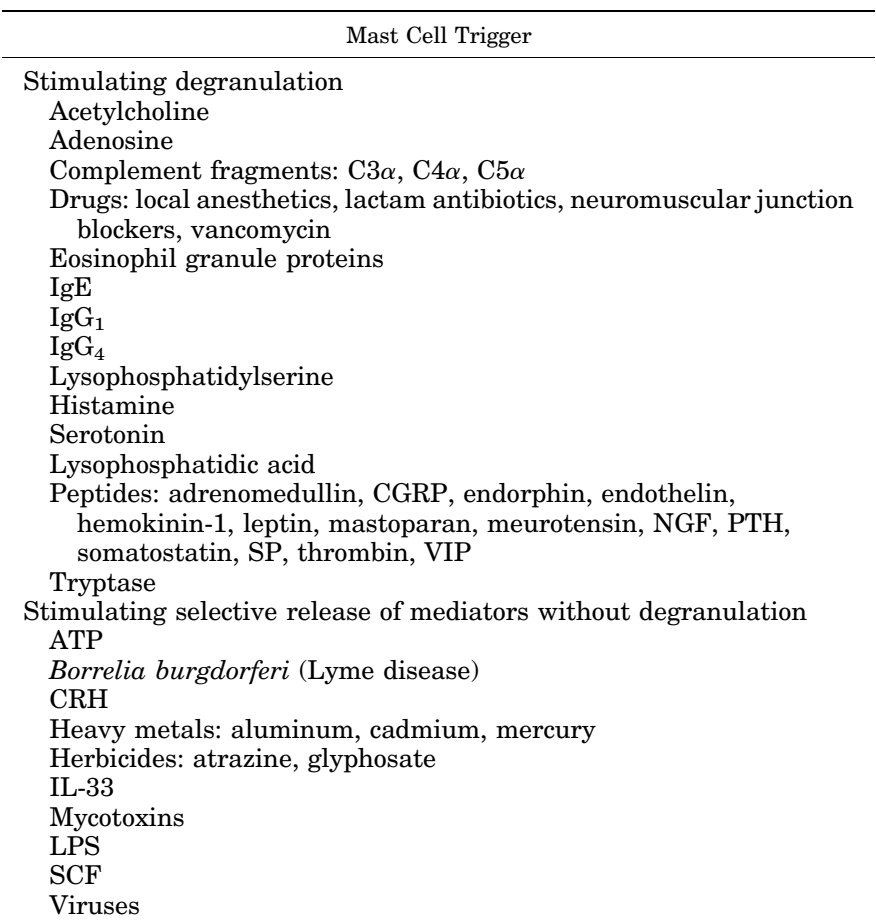

CGRP, calcitonin-gene related peptide; LPS, lipopolyssacharide; NGF, nerve growth factor; PTH, parathyroid hormone; SCF, stem cell factor; VIP, vasoactive intestinal polypeptide.

of patients with ME/CFS and correlated significantly with stress (Fletcher et al., 2010), since this peptide is known to stimulate mast cells (Mousli and Landry, 1994).

An important part of this process is that a combination of triggers is likely to play a more important pathogenetic role than individual ones. For instance, we reported that the combination of $\mathrm{CRH}$ and neurotensin has a synergistic action in stimulating vascular endothelial growth factor secretion without tryptase from human mast cells (Donelan et al., 2006), as well as in inducing the expression of each other's receptors on human mast cells (Alysandratos et al., 2012). More recently, we showed that the combination of substance P (SP) and IL-33 has synergistic action in stimulating TNF secretion without tryptase from human cultured mast cells (Taracanova et al., 2017).

$\mathrm{CRH}$ is often released together with another peptide, neurotensin, which is vasoactive (Leeman and Carraway, 1982) and has also been implicated in inflammation (Mustain et al., 2011) and neurologic diseases (Cáceda et al., 2006). Neurotensin is increased in the skin following acute stress (Theoharides et al., 1998) and increases vascular permeability, an effect synergistic with CRH (Crompton et al., 2003; Donelan et al., 2006).

Mast cells are also stimulated by the peptide SP (Church et al., 1991; Theoharides et al., 2010; Taracanova et al., 2017), initially characterized by Leeman and colleagues (Chang and Leeman, 1970; Carraway and Leeman, 1973) and shown to participate in inflammatory processes (Hökfelt et al., 2001; O'Connor et al., 2004; Douglas and Leeman, 2011; Mashaghi et al., 2016). IL-33 is a member of the IL- 1 family of cytokines and has emerged as an early warning sign (dubbed alarmin) (Moulin et al., 2007) in autoimmune or inflammatory process 
TABLE 4

Mast cell mediators

\begin{tabular}{|c|c|}
\hline Mediator & Pathophysiologic Effect \\
\hline \multicolumn{2}{|l|}{ Prestored } \\
\hline \multicolumn{2}{|l|}{ Biogenic amines } \\
\hline Dopamine & Neurotransmission \\
\hline Histamine & Vasodilation, angiogenesis, mitogenesis, pain \\
\hline 5-Hydroxytryptamine (5-HT, serotonin) & Vasoconstriction, pain \\
\hline \multicolumn{2}{|l|}{ Polyamines } \\
\hline Spermidine, spermine & Secretory granule stability, inhibition of secretion \\
\hline \multicolumn{2}{|r|}{ Secretory granule stabinty, innibition or secretion } \\
\hline $\begin{array}{l}\text { IL-8 (CXCL8), MCP-1 (CCL2), MCP-3 (CCL7), MCP-4, RANTES } \\
\text { (CCL5), Eotaxin (CCL11) }\end{array}$ & Chemoattraction and tissue infiltration of leukocytes \\
\hline \multicolumn{2}{|l|}{$\begin{array}{l}\text { Cytokines } \\
\text { Cotaxin (CLLII) }\end{array}$} \\
\hline IL-4, IL-5, IL-6, IL-15, IL-17, IL-31, IL-33, TNF & Immune cell maturation, inflammation \\
\hline \multicolumn{2}{|l|}{ Enzymes } \\
\hline Arylsulfatases A & Lipid/proteoglycan hydrolysis \\
\hline Beta-hexosaminidase & Degradation processes \\
\hline Beta-glucuronidase & Degradation processes \\
\hline Beta-glucosaminidase & Degradation processes \\
\hline Beta-D-galactosidaseses & Degradation processes \\
\hline Carboxypeptidase A & Peptide processing \\
\hline Cathepsins B,C, D, E, L & Degradation processes \\
\hline Chymase & Tissue damage, pain, angiotensin II synthesis \\
\hline Grnzyme B & Inflammation and preapoptotic effects \\
\hline Kinogenasesn & Synthesis of vasodilatory kinins, pain \\
\hline Phospholipases & Arachidonic acid generation \\
\hline Renin & Angiotensin II generation \\
\hline Tryptase, pain & Tissue damage, activation of PAR, inflammation, pain \\
\hline Metalloproteinases (CPA3, MMP9, ADAMTSS) & Tissue damage, modification of cytokines/chemokines \\
\hline \multicolumn{2}{|l|}{ Growth factors } \\
\hline b-FGF & Neovascularization \\
\hline NGF & Nerve growth, mast cell activation \\
\hline SCF mast cell growth and activation & Mast cell growth and activation \\
\hline TGF $\beta$ & Anti-inflammatory, profibrotic \\
\hline VEGF & Neovascularization, vasodilation \\
\hline \multicolumn{2}{|l|}{ Peptides } \\
\hline \multicolumn{2}{|l|}{ ACTH } \\
\hline Angiogenin & Neovascularization \\
\hline Angiopoietin & Neovascularization \\
\hline Corticotropin-releasing hormone & Inflammation, mast cell stimulus, vasodilation \\
\hline Endorphins & Analgesia \\
\hline Endothelin & Sepsis \\
\hline Hemokinin-1 & Inflammation, mast cell stimulus, pain, vasodilation \\
\hline Kinins (bradykinin) & Inflammation, mast cell stimulus, pain, vasodilation \\
\hline Leptin & Food intake regulator \\
\hline Meltonin & Biologic clock regulator \\
\hline Neurotensin & Inflammation, mast cell stimulus, vasodilation \\
\hline RANKL & Osteoclast differentiation and activation \\
\hline Somatostatin & Mast cell stimulant, antisecretory \\
\hline Substance P & Inflammation, mast cell stimulus, pain \\
\hline Urocortin & Inflammation, vasodilation \\
\hline Vasoactive intestinal peptide & Vasodilation, mast cell activation \\
\hline \multicolumn{2}{|l|}{ Proteoglycans } \\
\hline Chondroitin sulfate & Cartilage synthesis, anti-inflammatory \\
\hline Heparin & Angiogenesis, nerve growth factor stabilization \\
\hline Hyaluronic acid & Connective tissue, nerve growth factor stabilization \\
\hline Serglycin & Storage of granule proteases \\
\hline \multicolumn{2}{|l|}{ De novo synthesized } \\
\hline \multicolumn{2}{|l|}{ Chemokines } \\
\hline \multirow{2}{*}{\multicolumn{2}{|c|}{$\begin{array}{l}\text { CCL2, CXCL8, MIP- } 1 \alpha, \text { MCP-1 } \\
\text { Cytokines }\end{array}$}} \\
\hline & \\
\hline IL- $1,2,3,4,5,6,8,9,10,13,16$, and 18 & Inflammation, leukocyte migration, pain \\
\hline IFN- $\alpha$, IFN- $\beta$, IFN- $\gamma ;$ MIF; TGF $\beta$; TNF & Inflammation, leukocyte proliferation/activation \\
\hline \multicolumn{2}{|l|}{$\begin{array}{l}\text { IFN- } \alpha, \mathrm{IFN}-\beta, \mathrm{IF}-\gamma ; \mathrm{MIF} ; \mathrm{TGF} \beta ; \mathrm{TNF} \\
\text { Growth factors }\end{array}$} \\
\hline SCF, $\beta$-FGF, neurotrophin 3 , NGF, PDGF, TGF $\beta$, VEGF & Growth of a variety of cells \\
\hline Nitric oxide & Vasodilation \\
\hline Phospholipid metabolites & \\
\hline Leukotriene $\mathrm{B}_{4}$ & Leukocyte chemotaxis \\
\hline Leukotriene $\mathrm{C}_{4}$ & Vasoconstriction, pain \\
\hline Platelet activating factor & Platelet activation, vasodilation \\
\hline Prostaglandin $\mathrm{D}_{2}$ & Bronchonstriction, pain \\
\hline
\end{tabular}

IFN, interferon; MIF, macrophage inflammatory factor; MIP, macrophage inflammatory protein; NGF, nerve growth factor; PAR, protease activated receptors; PDGF, platelet-derived growth factor; RANKL, receptor activator of nuclear factor kappa-B ligand; SCF, stem cell factor; TGF $\beta$, transforming growth factor $\beta$; VEGF, vascular endothelial growth factor. 
TABLE 5

Microglia mediators

\begin{tabular}{ll}
\hline Cytokine & \multicolumn{1}{c}{ Chemokine } \\
\hline IL-1 $\beta$ & CCL2 \\
IL-6 & CXCL8 (IL-8) \\
TNF & CCL5 (MCP-1) \\
\hline
\end{tabular}

(Saluja et al., 2015; Theoharides et al., 2015a; Theoharides, 2016). IL-33 is secreted by fibroblasts and endothelial cells (Liew et al., 2010), and also from mast cells (Tung et al., 2014). IL-33 augments the effect of $\mathrm{IgE}$ on secretion of histamine from mast cells and basophils (Moulin et al., 2007; Silver et al., 2010).

Substance P stimulated secretion of vascular endothelial growth factor, an action augmented by IL-33 (Theoharides et al., 2010). We recently showed that stimulation of human mast cells by SP given together with IL-33 markedly increases secretion and gene expression of the proinflammatory cytokine, TNF (Taracanova et al., 2017) and of IL-1 $\beta$ (unpublished results). Interestingly, chronic rhinosinusitis, which is quite common in patients with ME/CFS as discussed previously, has been associated with high levels of nasal IL-33 (Ozturan et al., 2017), which could reach the hypothalamus through the cribriform plexus.

\section{Does Any Treatment Modality Work?}

There are currently no Food and Drug Administration approved drugs for the treatment of ME/CFS and the available psychological, physical, and pharmacological interventions do not appear to be effective (Bains, 2008; Pae et al., 2009; Morris and Maes, 2014; Collatz et al., 2016; Loades et al., 2016; Brigden et al., 2017; Castro-Marrero et al., 2017). Mitochondria appear as one appealing drug target for the treatment of ME/CFS, but other papers reported no apparent alteration in ATP production (Shungu et al., 2012). Chemokines and cytokines have been proposed as targets for neuroinflammatory disorders (Pranzatelli, 2018), but they have not been tried in ME/CFS.

The peroxisome proliferator-activated receptor agonist bezafibrate improves mitochondrial function by stimulating mitochondrial biogenesis and increasing the oxidative phosphorylation efficiency in a number of studies (Wang et al., 2010; Johri et al., 2012; Valero, 2014). It has also been suggested that since fatigue is associated with hypotension in ME/CFS patients, increasing blood pressure might present an effective therapeutic approach to this symptom. Even though previous studies using the mineralcorticoid fludrocortisone failed to show any improvement (Peterson et al., 1998; Rowe et al., 2016), use of the agonist midodrine to increase blood pressure has produced some improvement in relation to fatigue (Naschitz et al., 2004). Interestingly, angiotensin II inhibitors have been shown to increase mitochondrial membrane potential, improve mitochondrial function, and stimulate mitochondrial biogenesis (de Cavanagh et al., 2011; Morris and Maes, 2014). Indeed, blockade of angiotensin II has been shown to prevent the onset of type 2 diabetes mellitus in mice by increasing fat oxidation, decreasing muscle triglycerides, and improving glucose tolerance (Mitsuishi et al., 2009). The angiotensin receptor blocker telmisartan improves mitochondrial dysfunction by enhancing mitochondrial biogenesis and protecting vascular and endothelial cell damage (Takeuchi et al., 2013; Kurokawa et al., 2015). Similarly, the angiotensin receptor blocker losartan has been shown to improve mitochondrial respiratory chain function and coenzyme Q10 content in hypertensive animals (Sumbalová et al., 2010). However, given the blood pressure lowering effects of these agents, it is unlikely they will be useful in ME/CFS, except maybe in select patients.

Several natural compounds may have a beneficial effect on mitochondrial function. Magnesium ions play critical roles in energy metabolism and in maintaining normal muscle function by being a positively active regulator of glycolysis and of all enzymatic reactions involving phosphate group transfer from ATP (Dominguez et al., 2006; Morris and Maes, 2014). Several studies have demonstrated that magnesium ion supplements significantly increase muscle strength and maintain optimal physical activity performance in humans (Brilla and Haley, 1992; Newhouse and Finstad, 2000; Kass and Poeira, 2015; Zhang et al., 2017). In experimental animals, this improvement in exercise performance seems to occur via enhancing glucose availability in the brain and muscle, and via reducing/delaying lactate accumulation (Zhang et al., 2017). Magnesium sulfate may also improve mitochondrial respiratory function and prevent nitrous oxide production in the brain (Xu et al., 2002; Yang et al., 2007).

Coenzyme Q10 deficiency has been reported in patients with ME/CFS (Maes et al., 2009, 2012a,b; Filler et al., 2014). However, administration of coenzyme Q10 to patients with ME/CFS has failed to show any benefit (Campagnolo et al., 2017).

Naturally occurring flavonoids have potent antioxidant, antiinflammatory, and neuroprotective actions (Middleton et al., 2000; Guo et al., 2009; Xiao et al., 2011) and are generally considered safe (Kawanishi et al., 2005; Harwood et al., 2007; Theoharides et al., 2014). The flavonoid genistein attenuates muscle fatigue in humans by downregulating oxidative stress and enhancing antioxidant enzyme activity (Ding and Liu, 2011). The flavonoids epigallocatechin, naringin, and curcumin can ameliorate ME/CFS symptoms in experimental models (Gupta et al., 2009; Sachdeva et al., 2009, 2011; Vij et al., 2009). Other reports have documented similar chronic fatigue attenuating effects for the Astragalus flavonoids (Kuo et al., 2009) and olive extract (Gupta et al., 2010). The isoflavones genistein and daidzein have been shown to reverse the effects of polyinosinic:polycytidylic acid on mouse locomotor activity and brain inflammatory mediator expression in a mouse model of fatigue (Vasiadi et al., 2014). Quercetin appears to increase exercise tolerance by attenuating oxidative stress in mouse brain, while at the same time conferring antioxidant and anti-inflammatory actions (Kempuraj et al., 2005; Davis et al., 2009; Ishisaka et al., 2011).

Luteolin suppresses adipocyte activation of macrophages and inflammation (Ando et al., 2009; Deqiu et al., 2011), while it increases insulin sensitivity of the endothelium (Deqiu et al., 2011). Luteolin also inhibits mast cells (Asadi et al., 2010; Weng et al., 2015; Patel and Theoharides, 2017) and microglia (Jang et al., 2008; Patel et al., 2016). In this context, it is interesting that luteolin improved symptoms of autism spectrum disorder (Taliou et al., 2013; Tsilioni et al., 2015), post-Lyme syndrome (Theoharides and Stewart, 2016), and brain fog (Theoharides et al., 2015b) in open-label trials. We recently showed that tetramethoxyluteolin is more potent than luteolin in its ability to inhibit human cultured microglia (Patel et al., 2016) and mast cells (Patel and Theoharides, 2017). 
Intranasal administration of select flavonoids may reduce inflammation in the hypothalamus and correct the central pathogenesis of ME/CFS. For instance, intranasal administration of microvesicle-entrapped curcumin was shown to inhibit inflammation of the brain in a mouse model (Sun et al., 2010).

\section{Conclusions}

Overall, the ME/CFS phenotype has been associated with apparent abnormalities in the metabolic profile, possibly due to local inflammation in the hypothalamus. Novel treatment approaches are required to address the central pathogenic processes. Compounds that could inhibit inflammation in the brain such as tetramethoxyluteolin or the anti-inflammatory cytokine IL-37 (Dinarello et al., 2016; Mastrangelo et al., 2018) may be potential treatment options.

\section{Authorship Contributions}

Wrote or contributed to the writing of the manuscript: Hatziagelaki, Adamaki, Tsilioni, Dimitriadis, Theoharides.

\section{References}

Abbi B and Natelson BH (2013) Is chronic fatigue syndrome the same illness as fibromyalgia: evaluating the 'single syndrome' hypothesis. QJM 106:3-9.

Akin C (2014) Mast cell activation disorders. J Allergy Clin Immunol Pract 2: 252-257.e1, quiz 258.

Alevizos M, Karagkouni A, Panagiotidou S, Vasiadi M, and Theoharides TC (2014) Stress triggers coronary mast cells leading to cardiac events. Ann Allergy Asthma Immunol 112:309-316

Alysandratos KD, Asadi S, Angelidou A, Zhang B, Sismanopoulos N, Yang H, Critchfield A, and Theoharides TC (2012) Neurotensin and CRH interactions augment human mast cell activation. PLoS One 7:e48934.

Ando C, Takahashi N, Hirai S, Nishimura K, Lin S, Uemura T, Goto T, Yu R, Nakagami J, Murakami S, et al. (2009) Luteolin, a food-derived flavonoid, suppresses adipocyte-dependent activation of macrophages by inhibiting JNK activation. FEBS Lett 583:3649-3654.

Armstrong CW, McGregor NR, Butt HL, and Gooley PR (2014) Metabolism in chronic fatigue syndrome. Adv Clin Chem 66:121-172.

Armstrong CW, McGregor NR, Lewis DP, Butt HL, and Gooley PR (2015) Metabolic profiling reveals anomalous energy metabolism and oxidative stress pathways in chronic fatigue syndrome patients. Metabolomics 11:1626-1639.

Armstrong CW, McGregor NR, Sheedy JR, Buttfield I, Butt HL, and Gooley PR (2012) NMR metabolic profiling of serum identifies amino acid disturbances in chronic fatigue syndrome. Clin Chim Acta 413:1525-1531.

Asadi S, Zhang B, Weng Z, Angelidou A, Kempuraj D, Alysandratos KD, and Theoharides TC (2010) Luteolin and thiosalicylate inhibit $\mathrm{HgCl}_{2}$ and thimerosal-induced VEGF release from human mast cells. Int $J$ Immunopathol Pharmacol 23:1015-1020.

Azevedo A, Bettencourt P, Pimenta J, Friões F, Abreu-Lima C, Hense HW, and Barros H (2007) Clinical syndrome suggestive of heart failure is frequently attributable to non-cardiac disorders-population-based study. Eur J Heart Fail 9: 391-396.

Bachert C, Zhang N, Hellings PW, and Bousquet J (2018) Endotype-driven care pathways in patients with chronic rhinosinusitis. J Allergy Clin Immunol 141:1543-1551.

Bains W (2008) Treating chronic fatigue states as a disease of the regulation of energy metabolism. Med Hypotheses 71:481-488.

Bakken IJ, Tveito K, Gunnes N, Ghaderi S, Stoltenberg C, Trogstad L, Håberg SE and Magnus P (2014) Two age peaks in the incidence of chronic fatigue syndrome/myalgic encephalomyelitis: a population-based registry study from Norway 2008-2012. BMC Med 12:167.

Baraniuk JN and Ho Le U (2007) The nonallergic rhinitis of chronic fatigue syndrome. Clin Allergy Immunol 19:427-447.

Baraniuk JN and Shivapurkar N (2017) Exercise-induced changes in cerebrospinal fluid miRNAs in Gulf War illness, chronic fatigue syndrome and sedentary control subjects. Sci Rep 7:15338.

Baraniuk JN and Shivapurkar N (2018) Author correction: exercise-induced changes in cerebrospinal fluid miRNAs in Gulf War illness, chronic fatigue syndrome and sedentary control subjects. Sci Rep 8:6455.

Beaven MA (2009) Our perception of the mast cell from Paul Ehrlich to now. Eur $J$ Immunol 39:11-25.

Billing-Ross P, Germain A, Ye K, Keinan A, Gu Z, and Hanson MR (2016) Mitochondrial DNA variants correlate with symptoms in myalgic encephalomyelitis/ chronic fatigue syndrome. J Transl Med 14:19.

Booth NE, Myhill S, and McLaren-Howard J (2012) Mitochondrial dysfunction and the pathophysiology of myalgic encephalomyelitis/chronic fatigue syndrome (ME/CFS). Int J Clin Exp Med 5:208-220.

Bower JE (2012) Fatigue, brain, behavior, and immunity: summary of the 2012 Named Series on fatigue. Brain Behav Immun 26:1220-1223.

Bozzini S, Albergati A, Capelli E, Lorusso L, Gazzaruso C, Pelissero G, and Falcone C (2018) Cardiovascular characteristics of chronic fatigue syndrome. Biomed Rep 8:26-30.
Brenu EW, Ashton KJ, Batovska J, Staines DR, and Marshall-Gradisnik SM (2014) High-throughput sequencing of plasma microRNA in chronic fatigue syndrome/ myalgic encephalomyelitis. PLoS One 9:e102783.

Brenu EW, Ashton KJ, van Driel M, Staines DR, Peterson D, Atkinson GM, and Marshall-Gradisnik SM (2012) Cytotoxic lymphocyte microRNAs as prospective biomarkers for chronic fatigue syndrome/myalgic encephalomyelitis. $J$ Affect Disord 141:261-269.

Brenu EW, van Driel ML, Staines DR, Ashton KJ, Ramos SB, Keane J, Klimas NG, and Marshall-Gradisnik SM (2011) Immunological abnormalities as potential biomarkers in chronic fatigue syndrome/myalgic encephalomyelitis. J Transl Med 9:81.

Brigden A, Loades M, Abbott A, Bond-Kendall J, and Crawley E (2017) Practica management of chronic fatigue syndrome or myalgic encephalomyelitis in childhood. Arch Dis Child 102:981-986.

Brilla LR and Haley TF (1992) Effect of magnesium supplementation on strength training in humans. J Am Coll Nutr 11:326-329.

Brown AE, Jones DE, Walker M, and Newton JL (2015) Abnormalities of AMPK activation and glucose uptake in cultured skeletal muscle cells from individuals with chronic fatigue syndrome. PLoS One 10:e122982.

Brurberg KG, Fønhus MS, Larun L, Flottorp S, and Malterud K (2014) Case definitions for chronic fatigue syndrome/myalgic encephalomyelitis (CFS/ME): a systematic review. BMJ Open 4:e003973.

Cáceda R, Kinkead B, and Nemeroff CB (2006) Neurotensin: role in psychiatric and neurological diseases. Peptides 27:2385-2404.

Campagnolo N, Johnston S, Collatz A, Staines D, and Marshall-Gradisnik S (2017) Dietary and nutrition interventions for the therapeutic treatment of chronic fatigue syndrome/myalgic encephalomyelitis: a systematic review. J Hum Nutr Diet 30:247-259.

Cantó C and Auwerx J (2009) PGC-1alpha, SIRT1 and AMPK, an energy sensing network that controls energy expenditure. Curr Opin Lipidol 20:98-105.

Cao J, Papadopoulou N, Kempuraj D, Boucher WS, Sugimoto K, Cetrulo CL, and Theoharides TC (2005) Human mast cells express corticotropin-releasing hormone $(\mathrm{CRH})$ receptors and $\mathrm{CRH}$ leads to selective secretion of vascular endothelial growth factor. $J$ Immunol 174:7665-7675.

Capelli E, Lorusso L, Ghitti M, Venturini L, Cusa C, and Ricevuti G (2015) Chronic fatigue syndrome: features of a population of patients from northern Italy. Int $J$ Immunopathol Pharmacol 28:53-59.

Carraway R and Leeman SE (1973) The isolation of a new hypotensive peptide, neurotensin, from bovine hypothalami. J Biol Chem 248:6854-6861.

Carruthers BM (2007) Definitions and aetiology of myalgic encephalomyelitis: how the Canadian consensus clinical definition of myalgic encephalomyelitis works. $J$ Clin Pathol 60:117-119.

Carruthers BM, Jain AK, De Meirleir KL, Peterson DL, Klimas NG, Lerner AM, Bested AC, Flor-Henry P, Joshi P, Powles ACP, et al. (2003) Myalgic encephalomyelitis/chronic fatigue syndrome: clinical working case definition, diagnostic and treatment protocols. J Chronic Fatigue Syndr 11:7-115.

Carruthers BM, van de Sande MI, De Meirleir KL, Klimas NG, Broderick G, Mitchell T, Staines D, Powles AC, Speight N, Vallings R, et al. (2011) Myalgic encephalomyelitis: International Consensus Criteria. J Intern Med 270:327-338.

Castro-Marrero J, Sáez-Francàs N, Santillo D, and Alegre J (2017) Treatment and management of chronic fatigue syndrome/myalgic encephalomyelitis: all roads lead to Rome. Br J Pharmacol 174:345-369.

Chang MM and Leeman SE (1970) Isolation of a sialogogic peptide from bovine hypothalamic tissue and its characterization as substance P. J Biol Chem 245: 4784-4790.

Chester AC (2003) Symptoms of rhinosinusitis in patients with unexplained chronic fatigue or bodily pain: a pilot study. Arch Intern Med 163:1832-1836.

Chrousos GP (1995) The hypothalamic-pituitary-adrenal axis and immune-mediated inflammation. N Engl J Med 332:1351-1362.

Church MK, el-Lati S, and Caulfield JP (1991) Neuropeptide-induced secretion from human skin mast cells. Int Arch Allergy Appl Immunol 94:310-318.

Cleare AJ, Miell J, Heap E, Sookdeo S, Young L, Malhi GS, and O'Keane V (2001) Hypothalamo-pituitary-adrenal axis dysfunction in chronic fatigue syndrome, and the effects of low-dose hydrocortisone therapy. J Clin Endocrinol Metab 86 $3545-3554$

Collatz A, Johnston SC, Staines DR, and Marshall-Gradisnik SM (2016) A systematic review of drug therapies for chronic fatigue syndrome/myalgic encephalomyelitis. Clin Ther 38:1263-1271.e9.

Collin SM, Bakken IJ, Nazareth I, Crawley E, and White PD (2017) Trends in the incidence of chronic fatigue syndrome and fibromyalgia in the UK, 2001-2013: a Clinical Practice Research Datalink study. J R Soc Med 110:231-244.

Collins LV, Hajizadeh S, Holme E, Jonsson IM, and Tarkowski A (2004) Endogenously oxidized mitochondrial DNA induces in vivo and in vitro inflammatory responses. J Leukoc Biol 75:995-1000.

Conti P, Caraffa Al, Kritas SK, Ronconi G, Lessiani G, Toniato E, and Theoharides TC (2017) Mast cell, pro-inflammatory and anti-inflammatory: Jekyll and Hyde, the story continues. J Biol Regul Homeost Agents 31:263-267.

Cook DB, Nagelkirk PR, Poluri A, Mores J, and Natelson BH (2006) The influence of aerobic fitness and fibromyalgia on cardiorespiratory and perceptual responses to exercise in patients with chronic fatigue syndrome. Arthritis Rheum 54:3351-3362

Crawley E (2014) The epidemiology of chronic fatigue syndrome/myalgic encephalitis in children. Arch Dis Child 99:171-174.

Crawley E, Hunt L, and Stallard P (2009) Anxiety in children with CFS/ME. Eur Child Adolesc Psychiatry 18:683-689.

Crompton R, Clifton VL, Bisits AT, Read MA, Smith R, and Wright IM (2003) Corticotropin-releasing hormone causes vasodilation in human skin via mast celldependent pathways. J Clin Endocrinol Metab 88:5427-5432.

Davis JM, Murphy EA, Carmichael MD, and Davis B (2009) Quercetin increases brain and muscle mitochondrial biogenesis and exercise tolerance. Am J Physio Regul Integr Comp Physiol 296:R1071-R1077. 
Davis SD, Kator SF, Wonnett JA, Pappas BL, and Sall JL (2000) Neurally mediated hypotension in fatigued Gulf War veterans: a preliminary report. Am J Med Sci 319:89-95.

Daviss B (2005) Growing pains for metabolomics. Scientist 19:25-28.

de Cavanagh EM, Inserra F, and Ferder L (2011) Angiotensin II blockade: a strategy to slow ageing by protecting mitochondria? Cardiovasc Res 89:31-40.

Dekker JM, Girman C, Rhodes T, Nijpels G, Stehouwer CD, Bouter LM, and Heine RJ (2005) Metabolic syndrome and 10-year cardiovascular disease risk in the Hoorn study. Circulation 112:666-673.

Deqiu Z, Kang L, Jiali Y, Baolin L, and Gaolin L (2011) Luteolin inhibits inflammatory response and improves insulin sensitivity in the endothelium. Biochimie 93:506-512.

Dietert RR and Dietert JM (2008) Possible role for early-life immune insult including developmental immunotoxicity in chronic fatigue syndrome (CFS) or myalgic encephalomyelitis (ME). Toxicology 247:61-72.

Dinarello CA, Nold-Petry C, Nold M, Fujita M, Li S, Kim S, and Bufler P (2016) Suppression of innate inflammation and immunity by interleukin-37. Eur $J$ Immunol 46:1067-1081.

Ding W and Liu Y (2011) Genistein attenuates genioglossus muscle fatigue under chronic intermittent hypoxia by down-regulation of oxidative stress level and up-regulation of antioxidant enzyme activity through ERK1/2 signaling pathway. Oral Dis 17:677-684.

Dominguez LJ, Barbagallo M, Lauretani F, Bandinelli S, Bos A, Corsi AM, Simonsick EM, and Ferrucci L (2006) Magnesium and muscle performance in older persons: the InCHIANTI study. Am J Clin Nutr 84:419-426.

Donelan J, Boucher W, Papadopoulou N, Lytinas M, Papaliodis D, Dobner P, and Theoharides TC (2006) Corticotropin-releasing hormone induces skin vascular permeability through a neurotensin-dependent process. Proc Natl Acad Sci USA 103:7759-7764.

Douglas SD and Leeman SE (2011) Neurokinin-1 receptor: functional significance in the immune system in reference to selected infections and inflammation. Ann NY Acad Sci 1217:83-95.

Edvinsson L, Cervós-Navarro J, Larsson LI, Owman C, and Rönnberg AL (1977) Regional distribution of mast cells containing histamine, dopamine, or 5-hydroxytryptamine in the mammalian brain. Neurology 27:878-883.

Esposito P, Chandler N, Kandere K, Basu S, Jacobson S, Connolly R, Tutor D, and Theoharides TC (2002) Corticotropin-releasing hormone and brain mast cells regulate blood-brain-barrier permeability induced by acute stress. $J$ Pharmacol Exp Ther 303:1061-1066.

Filler K, Lyon D, Bennett J, McCain N, Elswick R, Lukkahatai N, and Saligan LN (2014) Association of mitochondrial dysfunction and fatigue: a review of the literature. BBA Clin 1:12-23.

Fletcher MA, Rosenthal M, Antoni M, Ironson G, Zeng XR, Barnes Z, Harvey JM, Hurwitz B, Levis S, Broderick G, et al. (2010) Plasma neuropeptide Y: a biomarker for symptom severity in chronic fatigue syndrome. Behav Brain Funct 6 76.

Fluge Ø, Mella O, Bruland O, Risa K, Dyrstad SE, Alme K, Rekeland IG, Sapkota D, Røsland GV, Fosså A, et al. (2016) Metabolic profiling indicates impaired pyruvate dehydrogenase function in myalgic encephalopathy/chronic fatigue syndrome. JCI Insight 1:e89376.

Frémont M, Metzger K, Rady H, Hulstaert J, and De Meirleir K (2009) Detection of herpesviruses and parvovirus B19 in gastric and intestinal mucosa of chronic fatigue syndrome patients. In Vivo 23:209-213.

Frith J, Zalewski P, Klawe JJ, Pairman J, Bitner A, Tafil-Klawe M, and Newton JL (2012) Impaired blood pressure variability in chronic fatigue syndrome-a potential biomarker. QJM 105:831-838.

Fukuda K, Straus SE, Hickie I, Sharpe MC, Dobbins JG, and Komaroff A; International Chronic Fatigue Syndrome Study Group (1994) The chronic fatigue syndrome: a comprehensive approach to its definition and study. Ann Intern Med 121:953-959.

Galli SJ, Tsai M, and Piliponsky AM (2008) The development of allergic inflammation. Nature 454:445-454.

Ganiats TG (2015) Redefining the chronic fatigue syndrome. Ann Intern Med 162 653-654

Georgiades E, Behan WM, Kilduff LP, Hadjicharalambous M, Mackie EE, Wilson J, Ward SA, and Pitsiladis YP (2003) Chronic fatigue syndrome: new evidence for a central fatigue disorder. Clin Sci (Lond) 105:213-218.

Germain A, Ruppert D, Levine SM, and Hanson MR (2017) Metabolic profiling of a myalgic encephalomyelitis/chronic fatigue syndrome discovery cohort reveals disturbances in fatty acid and lipid metabolism. Mol Biosyst 13:371-379.

Gerwyn M and Maes M (2017) Mechanisms explaining muscle fatigue and muscle pain in patients with myalgic encephalomyelitis/chronic fatigue syndrome (ME/CFS): a review of recent findings. Curr Rheumatol Rep 19:1.

Glassford JA (2017) The neuroinflammatory etiopathology of myalgic encephalomyelitis/chronic fatigue syndrome (ME/CFS). Front Physiol 8:88.

Gong J, Yang NS, Croft M, Weng IC, Sun L, Liu FT, and Chen SS (2010) The antigen presentation function of bone marrow-derived mast cells is spatiotemporally restricted to a subset expressing high levels of cell surface FceRI and MHC II. BMC Immunol 11:34.

Gorman GS, Elson JL, Newman J, Payne B, McFarland R, Newton JL, and Turnbull DM (2015) Perceived fatigue is highly prevalent and debilitating in patients with mitochondrial disease. Neuromuscul Disord 25:563-566.

Guo W, Kong E, and Meydani M (2009) Dietary polyphenols, inflammation, and cancer. Nutr Cancer 61:807-810.

Gupta A, Vij G, and Chopra K (2010) Possible role of oxidative stress and immunological activation in mouse model of chronic fatigue syndrome and its attenuation by olive extract. $J$ Neuroimmunol 226:3-7.

Gupta A, Vij G, Sharma S, Tirkey N, Rishi P, and Chopra K (2009) Curcumin, a polyphenolic antioxidant, attenuates chronic fatigue syndrome in murine water immersion stress model. Immunobiology 214:33-39.
Gwini SM, Forbes AB, Sim MR, and Kelsall HL (2016) Multisymptom illness in Gulf War veterans: a systematic review and meta-analysis. J Occup Environ Med 58: $659-667$.

Haney E, Smith ME, McDonagh M, Pappas M, Daeges M, Wasson N, and Nelson HD (2015) Diagnostic methods for myalgic encephalomyelitis/chronic fatigue syndrome: a systematic review for a National Institutes of Health Pathways to Prevention Workshop. Ann Intern Med 162:834-840.

Hanson SJ, Gause W, and Natelson B (2001) Detection of immunologically significant factors for chronic fatigue syndrome using neural-network classifiers. Clin Diagn Lab Immunol 8:658-662.

Harwood M, Danielewska-Nikiel B, Borzelleca JF, Flamm GW, Williams GM, and Lines TC (2007) A critical review of the data related to the safety of quercetin and lack of evidence of in vivo toxicity, including lack of genotoxic/carcinogenic properties. Food Chem Toxicol 45:2179-2205.

Hökfelt T, Pernow B, and Wahren J (2001) Substance P: a pioneer amongst neuropeptides. J Intern Med 249:27-40.

Hollingsworth KG, Jones DE, Taylor R, Blamire AM, and Newton JL (2010) Impaired cardiovascular response to standing in chronic fatigue syndrome. Eur J Clin Invest 40:608-615.

Holgate ST, Komaroff AL, Mangan D, and Wessely S (2011) Chronic fatigue syndrome: understanding a complex illness. Nature Rev Neurocsi 12(9):539-544.

Hornig M, Gottschalk CG, Eddy ML, Che X, Ukaigwe JE, Peterson DL, and Lipkin WI (2017) Immune network analysis of cerebrospinal fluid in myalgic encephalomyelitis/chronic fatigue syndrome with atypical and classical presentations. Transl Psychiatry 7:e1080

Hornig M, Gottschalk G, Peterson DL, Knox KK, Schultz AF, Eddy ML, Che X, and Lipkin WI (2016) Cytokine network analysis of cerebrospinal fluid in myalgic encephalomyelitis/chronic fatigue syndrome. Mol Psychiatry 21:261-269.

Hornig M, Montoya JG, Klimas NG, Levine S, Felsenstein D, Bateman L, Peterson DL, Gottschalk CG, Schultz AF, Che X, et al. (2015) Distinct plasma immune signatures in ME/CFS are present early in the course of illness. Sci Adv 1 e1400121.

Ishisaka A, Ichikawa S, Sakakibara H, Piskula MK, Nakamura T, Kato Y, Ito M, Miyamoto K, Tsuji A, Kawai Y, et al. (2011) Accumulation of orally administered quercetin in brain tissue and its antioxidative effects in rats. Free Radic Biol Med 51:1329-1336.

Isomaa B, Almgren P, Tuomi T, Forsén B, Lahti K, Nissén M, Taskinen MR, and Groop L (2001) Cardiovascular morbidity and mortality associated with the metabolic syndrome. Diabetes Care 24:683-689.

Jang S, Kelley KW, and Johnson RW (2008) Luteolin reduces IL-6 production in microglia by inhibiting JNK phosphorylation and activation of AP-1. Proc Natl Acad Sci USA 105:7534-7539.

Jason LA, Benton MC, Valentine L, Johnson A, and Torres-Harding S (2008) The economic impact of ME/CFS: individual and societal costs. Dyn Med 7:6.

Jason LA, Jordan K, Miike T, Bell DS, Lapp C, Torres-Harding S, Rowe K, Gurwitt A, De Meirleir K, Van Hoof ELS, et al. (2006) A pediatric case definition for myalgic encephalomyelitis and chronic fatigue syndrome. J Chronic Fatigue Syndr 13:1-44.

Jason LA, Porter N, Brown M, Anderson V, Brown A, Hunnell J, and Lerch A (2009) CFS: a review of epidemiology and natural history studies. Bull IACFS ME 17: 88-106.

Jiang W, Babyak M, Krantz DS, Waugh RA, Coleman RE, Hanson MM, Frid DJ, McNulty S, Morris JJ, O'Connor CM, et al. (1996) Mental stress-induced myocardial ischemia and cardiac events. JAMA 275:1651-1656.

Johri A, Calingasan NY, Hennessey TM, Sharma A, Yang L, Wille E, Chandra A and Beal MF (2012) Pharmacologic activation of mitochondrial biogenesis exerts widespread beneficial effects in a transgenic mouse model of Huntington's disease. Hum Mol Genet 21:1124-1137.

Jones MG, Cooper E, Amjad S, Goodwin CS, Barron JL, and Chalmers RA (2005) Urinary and plasma organic acids and amino acids in chronic fatigue syndrome. Clin Chim Acta 361:150-158.

Kass LS and Poeira F (2015) The effect of acute vs chronic magnesium supplementation on exercise and recovery on resistance exercise, blood pressure and tota peripheral resistance on normotensive adults. J Int Soc Sports Nutr 12:19.

Katz BZ, Shiraishi Y, Mears CJ, Binns HJ, and Taylor R (2009) Chronic fatigue syndrome after infectious mononucleosis in adolescents. Pediatrics 124:189-193.

Kaur J (2014) A comprehensive review on metabolic syndrome. Cardiol Res Pract 2014:943162.

Kawanishi S, Oikawa S, and Murata M (2005) Evaluation for safety of antioxidant chemopreventive agents. Antioxid Redox Signal 7:1728-1739.

Keller BA, Pryor JL, and Giloteaux L (2014) Inability of myalgic encephalomyelitis/chronic fatigue syndrome patients to reproduce $\mathrm{VO}_{2}$ peak indicates functional impairment. J Transl Med 12:104.

Kempuraj D, Madhappan B, Christodoulou S, Boucher W, Cao J, Papadopoulou N, Cetrulo CL, and Theoharides TC (2005) Flavonols inhibit proinflammatory mediator release, intracellular calcium ion levels and protein kinase $\mathrm{C}$ theta phosphorylation in human mast cells. Br J Pharmacol 145:934-944.

Kempuraj D, Papadopoulou NG, Lytinas M, Huang M, Kandere-Grzybowska K, Madhappan B, Boucher W, Christodoulou S, Athanassiou A, and Theoharides TC (2004) Corticotropin-releasing hormone and its structurally related urocortin are synthesized and secreted by human mast cells. Endocrinology 145:43-48.

Kennedy G, Spence VA, McLaren M, Hill A, Underwood C, and Belch JJ (2005) Oxidative stress levels are raised in chronic fatigue syndrome and are associated with clinical symptoms. Free Radic Biol Med 39:584-589.

Klimas NG, Broderick G, and Fletcher MA (2012) Biomarkers for chronic fatigue. Brain Behav Immun 26:1202-1210.

Komaroff AL (2015) Myalgic encephalomyelitis/chronic fatigue syndrome: a real illness. Ann Intern Med 162:871-872.

Krantz DS, Sheps DS, Carney RM, and Natelson BH (2000) Effects of mental stress in patients with coronary artery disease: evidence and clinical implications. JAMA 283:1800-1802. 
Kuo YH, Tsai WJ, Loke SH, Wu TS, and Chiou WF (2009) Astragalus membranaceus flavonoids (AMF) ameliorate chronic fatigue syndrome induced by food intake restriction plus forced swimming. J Ethnopharmacol 122:28-34

Kurokawa H, Sugiyama S, Nozaki T, Sugamura K, Toyama K, Matsubara J, Fujisue K, Ohba K, Maeda H, Konishi M, et al. (2015) Telmisartan enhances mitochondrial activity and alters cellular functions in human coronary artery endothelial cells via AMP-activated protein kinase pathway. Atherosclerosis 239: 375-385.

Leeman SE and Carraway RE (1982) Neurotensin: discovery, isolation, characterization, synthesis and possible physiological roles. Ann N Y Acad Sci 400:1-16.

Li C, Ford ES, McGuire LC, and Mokdad AH (2007) Association of metabolic syndrome and insulin resistance with congestive heart failure: findings from the Third National Health and Nutrition Examination Survey. $J$ Epidemiol Community Health 61:67-73.

Libby P, Ridker PM, and Maseri A (2002) Inflammation and atherosclerosis. Circulation 105:1135-1143.

Liew FY, Pitman NI, and McInnes IB (2010) Disease-associated functions of IL-33: the new kid in the IL-1 family. Nat Rev Immunol 10:103-110.

Loades ME, Sheils EA, and Crawley E (2016) Treatment for paediatric chronic fatigue syndrome or myalgic encephalomyelitis (CFS/ME) and comorbid depression: a systematic review. BMJ Open 6:e012271.

Loevinger BL, Muller D, Alonso C, and Coe CL (2007) Metabolic syndrome in women with chronic pain. Metabolism 56:87-93.

Louveau A, Smirnov I, Keyes TJ, Eccles JD, Rouhani SJ, Peske JD, Derecki NC, Castle D, Mandell JW, Lee KS, et al. (2015) Structural and functional features of central nervous system lymphatic vessels. Nature 523:337-341.

Maes M, Mihaylova I, Kubera M, Uytterhoeven M, Vrydags N, and Bosmans E (2009) Coenzyme Q10 deficiency in myalgic encephalomyelitis/chronic fatigue syndrome (ME/CFS) is related to fatigue, autonomic and neurocognitive symptoms and is another risk factor explaining the early mortality in ME/CFS due to cardiovascular disorder. Neuroendocrinol Lett 30:470-476.

Maes M, Twisk FN, and Johnson C (2012a) Myalgic encephalomyelitis (ME), chronic fatigue syndrome (CFS), and chronic fatigue (CF) are distinguished accurately: results of supervised learning techniques applied on clinical and inflammatory data. Psychiatry Res 200:754-760.

Maes M, Twisk FN, Kubera M, and Ringel K (2012b) Evidence for inflammation and activation of cell-mediated immunity in myalgic encephalomyelitis/chronic fatigue syndrome (ME/CFS): increased interleukin-1, tumor necrosis factor- $\alpha$, PMN-elastase, lysozyme and neopterin. J Affect Disord 136:933-939

Maloney EM, Boneva R, Nater UM, and Reeves WC (2009) Chronic fatigue syndrome and high allostatic load: results from a population-based case-control study in Georgia. Psychosom Med 71:549-556.

Marques PE, Amaral SS, Pires DA, Nogueira LL, Soriani FM, Lima BH, Lopes GA, Russo RC, Avila TV, Melgaço JG, et al. (2012) Chemokines and mitochondrial products activate neutrophils to amplify organ injury during mouse acute liver failure. Hepatology 56:1971-1982.

Martínez-Martínez LA, Mora T, Vargas A, Fuentes-Iniestra M, and Martínez-Lavín M (2014) Sympathetic nervous system dysfunction in fibromyalgia, chronic fatigue syndrome, irritable bowel syndrome, and interstitial cystitis: a review of casecontrol studies. J Clin Rheumatol 20:146-150.

Mashaghi A, Marmalidou A, Tehrani M, Grace PM, Pothoulakis C, and Dana R (2016) Neuropeptide substance P and the immune response. Cell Mol Life Sci 73: $4249-4264$

Mastrangelo F, Frydas I, Ronconi G, Kritas SK, Tettamanti L, Caraffa A, D’Ovidio C, Younes A, Gallenga CE, and Conti P (2018) Low-grade chronic inflammation mediated by mast cells in fibromyalgia: role of IL-37. J Biol Regul Homeost Agents 32: 195-198.

Matusik P, Guzik B, Weber C, and Guzik TJ (2012) Do we know enough about the immune pathogenesis of acute coronary syndromes to improve clinical practice? Thromb Haemost 108:443-456.

McCully KK and Natelson BH (1999) Impaired oxygen delivery to muscle in chronic fatigue syndrome. Clin Sci (Lond) 97:603-608, discussion 611-613.

McCully KK, Smith S, Rajaei S, Leigh JS Jr, and Natelson BH (2004) Muscle metabolism with blood flow restriction in chronic fatigue syndrome. $J$ Appl Physiol (1985) 96:871-878.

Meeus M, Goubert D, De Backer F, Struyf F, Hermans L, Coppieters I, De Wandele I, Da Silva H, and Calders P (2013) Heart rate variability in patients with fibromyalgia and patients with chronic fatigue syndrome: a systematic review. Semin Arthritis Rheum 43:279-287.

Middleton E Jr, Kandaswami C, and Theoharides TC (2000) The effects of plant flavonoids on mammalian cells: implications for inflammation, heart disease, and cancer. Pharmacol Rev 52:673-751.

Mitsuishi M, Miyashita K, Muraki A, and Itoh H (2009) Angiotensin II reduces mitochondrial content in skeletal muscle and affects glycemic control. Diabetes 58: $710-717$.

Miwa K and Fujita M (2009) Cardiovascular dysfunction with low cardiac output due to a small heart in patients with chronic fatigue syndrome. Intern Med 48:1849-1854.

Monro JA and Puri BK (2018) A molecular neurobiological approach to understanding the aetiology of chronic fatigue syndrome (myalgic encephalomyelitis or systemic exertion intolerance disease) with treatment implications. Mol Neurobiol 55:7377-7388.

Morris G, Anderson G, and Maes M (2017) Hypothalamic-pituitary-adrenal hypofunction in myalgic encephalomyelitis (ME)/chronic fatigue syndrome (CFS) as a consequence of activated immune-inflammatory and oxidative and nitrosative pathways. Mol Neurobiol 54:6806-6819.

Morris G, Berk M, Galecki P, and Maes M (2014) The emerging role of autoimmunity in myalgic encephalomyelitis/chronic fatigue syndrome (ME/cfs). Mol Neurobiol 49 $741-756$.

Morris G and Maes M (2012) Increased nuclear factor- $\kappa$ B and loss of p53 are key mechanisms in myalgic encephalomyelitis/chronic fatigue syndrome (ME/CFS). Med Hypotheses 79:607-613.
Morris G and Maes M (2013) Myalgic encephalomyelitis/chronic fatigue syndrome and encephalomyelitis disseminata/multiple sclerosis show remarkable levels of similarity in phenomenology and neuroimmune characteristics. BMC Med 11: 205.

Morris G and Maes M (2014) Mitochondrial dysfunctions in myalgic encephalomyelitis/chronic fatigue syndrome explained by activated immuno-inflammatory, oxidative and nitrosative stress pathways. Metab Brain Dis 29:19-36.

Morris G, Stubbs B, Köhler CA, Walder K, Slyepchenko A, Berk M, and Carvalho AF (2018) The putative role of oxidative stress and inflammation in the pathophysiology of sleep dysfunction across neuropsychiatric disorders: focus on chronic fatigue syndrome, bipolar disorder and multiple sclerosis. Sleep Med Rev DOI: 10.1016/j.smrv.2018.03.007 [published ahead of print]

Mottillo S, Filion KB, Genest J, Joseph L, Pilote L, Poirier P, Rinfret S, Schiffrin EL and Eisenberg MJ (2010) The metabolic syndrome and cardiovascular risk a systematic review and meta-analysis. J Am Coll Cardiol 56:1113-1132.

Moulin D, Donzé O, Talabot-Ayer D, Mézin F, Palmer G, and Gabay C (2007) Interleukin (IL)-33 induces the release of pro-inflammatory mediators by mast cells. Cytokine 40:216-225.

Mousli M and Landry Y (1994) Role of positive charges of neuropeptide Y fragments in mast cell activation. Agents Actions 41:C41-C42.

Mukai K, Tsai M, Saito H, and Galli SJ (2018) Mast cells as sources of cytokines, chemokines, and growth factors. Immunol Rev 282:121-150.

Murrough JW, Mao X, Collins KA, Kelly C, Andrade G, Nestadt P, Levine SM, Mathew SJ, and Shungu DC (2010) Increased ventricular lactate in chronic fatigue syndrome measured by $1 \mathrm{H}$ MRS imaging at $3.0 \mathrm{~T}$. II: comparison with major depressive disorder. NMR Biomed 23:643-650.

Mustain WC, Rychahou PG, and Evers BM (2011) The role of neurotensin in physiologic and pathologic processes. Curr Opin Endocrinol Diabetes Obes 18:75-82

Myhill S, Booth NE, and McLaren-Howard J (2009) Chronic fatigue syndrome and mitochondrial dysfunction. Int J Clin Exp Med 2:1-16.

Myhill S, Booth NE, and McLaren-Howard J (2013) Targeting mitochondrial dysfunction in the treatment of myalgic encephalomyelitis/chronic fatigue syndrome (ME/CFS) - a clinical audit. Int J Clin Exp Med 6:1-15.

Nacul LC, Lacerda EM, Pheby D, Campion P, Molokhia M, Fayyaz S, Leite JC, Poland F, Howe A, and Drachler ML (2011) Prevalence of myalgic encephalomyelitis/chronic fatigue syndrome (ME/CFS) in three regions of England: a repeated cross-sectional study in primary care. BMC Med 9:91.

Nadjar A, Wigren HM, and Tremblay ME (2017) Roles of microglial phagocytosis and inflammatory mediators in the pathophysiology of sleep disorders. Front Cell Neurosci 11:250

Nagy-Szakal D, Barupal DK, Lee B, Che X, Williams BL, Kahn EJR, Ukaigwe JE, Bateman L, Klimas NG, Komaroff AL, et al. (2018) Insights into myalgic encephalomyelitis/chronic fatigue syndrome phenotypes through comprehensive metabolomics. Sci Rep 8:10056

Najam SS, Zglinicki B, Vinnikov IA, and Konopka W (2018) MicroRNAs in the hypothalamic control of energy homeostasis. Cell Tissue Res DOI: 10.1007/s00441018-2876-0 [published ahead of print].

Nakamura T, Schwander S, Donnelly R, Cook DB, Ortega F, Togo F, Yamamoto Y, Cherniack NS, Klapholz M, Rapoport D, et al. (2013) Exercise and sleep deprivation do not change cytokine expression levels in patients with chronic fatigue syndrome. Clin Vaccine Immunol 20:1736-1742.

Nakamura T, Schwander SK, Donnelly R, Ortega F, Togo F, Broderick G, Yamamoto Y, Cherniack NS, Rapoport D, and Natelson BH (2010) Cytokines across the night in chronic fatigue syndrome with and without fibromyalgia. Clin Vaccine Immunol 17:582-587.

Nakatomi Y, Mizuno K, Ishii A, Wada Y, Tanaka M, Tazawa S, Onoe K, Fukuda S, Kawabe J, Takahashi K, et al. (2014) Neuroinflammation in patients with chronic fatigue syndrome/myalgic encephalomyelitis: an ${ }^{11} \mathrm{C}$-(R)-PK11195 PET study. $J$ Nucl Med 55:945-950.

Naschitz J, Dreyfuss D, Yeshurun D, and Rosner I (2004) Midodrine treatment for chronic fatigue syndrome. Postgrad Med J 80:230-232.

Natelson BH (2001) Chronic fatigue syndrome. JAMA 285:2557-2559.

Natelson BH, Intriligator R, Cherniack NS, Chandler HK, and Stewart JM (2007) Hypocapnia is a biological marker for orthostatic intolerance in some patients with chronic fatigue syndrome. Dyn Med 6:2.

Naviaux RK, Naviaux JC, Li K, Bright AT, Alaynick WA, Wang L, Baxter A, Nathan N, Anderson W, and Gordon E (2016) Metabolic features of chronic fatigue syndrome. Proc Natl Acad Sci USA 113:E5472-E5480.

Newhouse IJ and Finstad EW (2000) The effects of magnesium supplementation on exercise performance. Clin J Sport Med 10:195-200.

Newton JL, Sheth A, Shin J, Pairman J, Wilton K, Burt JA, and Jones DE (2009) Lower ambulatory blood pressure in chronic fatigue syndrome. Psychosom Med 71:361-365.

Nguyen T, Johnston S, Chacko A, Gibson D, Cepon J, Smith P, Staines D, and Marshall-Gradisnik S (2017) Novel characterisation of mast cell phenotypes from peripheral blood mononuclear cells in chronic fatigue syndrome/myalgic encephalomyelitis patients. Asian Pac J Allergy Immunol 35:75-81.

Niblett SH, King KE, Dunstan RH, Clifton-Bligh P, Hoskin LA, Roberts TK, Fulcher GR, McGregor NR, Dunsmore JC, Butt HL, et al. (2007) Hematologic and urinary excretion anomalies in patients with chronic fatigue syndrome. Exp Biol Med (Maywood) 232:1041-1049.

Nijhof SL, Maijer K, Bleijenberg G, Uiterwaal CS, Kimpen JL, and van de Putte EM (2011) Adolescent chronic fatigue syndrome: prevalence, incidence, and morbidity. Pediatrics 127:e1169-e1175.

Nijs J, Nees A, Paul L, De Kooning M, Ickmans K, Meeus M, and Van Oosterwijck J (2014) Altered immune response to exercise in patients with chronic fatigue syndrome/myalgic encephalomyelitis: a systematic literature review. Exerc Immunol Rev 20:94-116.

O'Connor TM, O'Connell J, O'Brien DI, Goode T, Bredin CP, and Shanahan F (2004) The role of substance P in inflammatory disease. J Cell Physiol 201:167-180. 
O'Kane M, Murphy EP, and Kirby B (2006) The role of corticotropin-releasing hormone in immune-mediated cutaneous inflammatory disease. Exp Dermatol 15: $143-153$.

Ozturan A, Eyigor H, Eyigor M, Osma U, Yilmaz MD, Selcuk OT, Renda L, and Gultekin M (2017) The role of IL-25 and IL-33 in chronic rhinosinusitis with or without nasal polyps. Eur Arch Otorhinolaryngol 274:283-288.

Pae CU, Marks DM, Patkar AA, Masand PS, Luyten P, and Serretti A (2009) Pharmacological treatment of chronic fatigue syndrome: focusing on the role of antidepressants. Expert Opin Pharmacother 10:1561-1570.

Pang X, Letourneau R, Rozniecki JJ, Wang L, and Theoharides TC (1996) Definitive characterization of rat hypothalamic mast cells. Neuroscience 73:889-902.

Patel AB and Theoharides TC (2017) Methoxyluteolin inhibits neuropeptidestimulated proinflammatory mediator release via mTOR activation from human mast cells. J Pharmacol Exp Ther 361:462-471.

Patel AB, Tsilioni I, Leeman SE, and Theoharides TC (2016) Neurotensin stimulates sortilin and mTOR in human microglia inhibitable by methoxyluteolin, a potential therapeutic target for autism. Proc Natl Acad Sci USA 113:E7049-E7058.

Pejovic S, Natelson BH, Basta M, Fernandez-Mendoza J, Mahr F, and Vgontzas AN (2015) Chronic fatigue syndrome and fibromyalgia in diagnosed sleep disorders: a further test of the 'unitary' hypothesis. BMC Neurol 15:53.

Petersen KF and Shulman GI (2006) Etiology of insulin resistance. Am J Med 119 (Suppl 1):S10-S16.

Peterson D, McCarthy EW, Gottschalk G, Ramos S, Nguyen T, Staines D, and Marshall-Gradisnik S (2015) Cytokines in the cerebrospinal fluids of patients with chronic fatigue syndrome/myalgic encephalomyelitis. Mediators Inflamm 929720.

Peterson PK, Pheley A, Schroeppel J, Schenck C, Marshall P, Kind A, Haugland JM, Lambrecht LJ, Swan S, and Goldsmith S (1998) A preliminary placebo-controlled crossover trial of fludrocortisone for chronic fatigue syndrome. Arch Intern Med 158:908-914.

Petra AI, Panagiotidou S, Hatziagelaki E, Stewart JM, Conti P, and Theoharides TC (2015) Gut-microbiota-brain axis and its effect on neuropsychiatric disorders with suspected immune dysregulation. Clin Ther 37:984-995.

Petty RD, McCarthy NE, Le Dieu R, and Kerr JR (2016) MicroRNAs hsa-miR-99b, hsa-miR-330, hsa-miR-126 and hsa-miR-30c: potential diagnostic biomarkers in natural killer (NK) cells of patients with chronic fatigue syndrome (CFS)/myalgic encephalomyelitis (ME). PLoS One 11:e0150904.

Pranzatelli MR (2018) Advances in biomarker-guided therapy for pediatric- and adult-onset neuroinflammatory disorders: targeting chemokines/cytokines. Front Immunol 9:557.

Ravindran MK, Zheng Y, Timbol C, Merck SJ, and Baraniuk JN (2011) Migraine headaches in chronic fatigue syndrome (CFS): comparison of two prospective crosssectional studies. BMC Neurol 11:30.

Repka-Ramirez S, Naranch K, Park YJ, Clauw D, and Baraniuk JN (2002) Cytokines in nasal lavage fluids from acute sinusitis, allergic rhinitis, and chronic fatigue syndrome subjects. Allergy Asthma Proc 23:185-190.

Robuffo I, Toniato E, Tettamanti L, Mastrangelo F, Ronconi G, Frydas I, Caraffa A, Kritas SK, and Conti P (2017) Mast cell in innate immunity mediated by proinflammatory and antiinflammatory IL-1 family members. J Biol Regul Homeost Agents 31:837-842.

Rowe PC, Fontaine KR, Lauver M, Jasion SE, Marden CL, Moni M, Thompson CB, and Violand RL (2016) Neuromuscular strain increases symptom intensity in chronic fatigue syndrome. PLoS One 11:e0159386.

Sachdeva AK, Kuhad A, and Chopra K (2011) Epigallocatechin gallate ameliorates behavioral and biochemical deficits in rat model of load-induced chronic fatigue syndrome. Brain Res Bull 86:165-172.

Sachdeva AK, Kuhad A, Tiwari V, and Chopra K (2009) Epigallocatechin gallate ameliorates chronic fatigue syndrome in mice: behavioral and biochemical evidence. Behav Brain Res 205:414-420.

Saluja R, Ketelaar ME, Hawro T, Church MK, Maurer M, and Nawijn MC (2015) The role of the IL-33/IL-1RL1 axis in mast cell and basophil activation in allergic disorders. Mol Immunol 63:80-85.

Scheibenbogen C, Freitag H, Blanco J, Capelli E, Lacerda E, Authier J, Meeus M, Castro Marrero J, Nora-Krukle Z, Oltra E, et al. (2017) The European ME/CFS biomarker landscape project: an initiative of the European network EUROMENE. $J$ Transl Med 15:162.

Schoeman EM, Van Der Westhuizen FH, Erasmus E, van Dyk E, Knowles CV, Al Ali S, Ng WF, Taylor RW, Newton JL, and Elson JL (2017) Clinically proven mtDNA mutations are not common in those with chronic fatigue syndrome. $B M C$ Med Genet 18:29.

Shungu DC, Weiduschat N, Murrough JW, Mao X, Pillemer S, Dyke JP, Medow MS, Natelson BH, Stewart JM, and Mathew SJ (2012) Increased ventricular lactate in chronic fatigue syndrome. III. Relationships to cortical glutathione and clinical symptoms implicate oxidative stress in disorder pathophysiology. NMR Biomed $\mathbf{2 5}$ 1073-1087.

Silver MR, Margulis A, Wood N, Goldman SJ, Kasaian M, and Chaudhary D (2010) IL-33 synergizes with IgE-dependent and IgE-independent agents to promote mast cell and basophil activation. Inflamm Res 59:207-218

Sismanopoulos N, Delivanis DA, Mavrommati D, Hatziagelaki E, Conti P, and Theoharides TC (2013) Do mast cells link obesity and asthma? Allergy 68:8-15.

Slominski A (2009) On the role of the corticotropin-releasing hormone signalling system in the aetiology of inflammatory skin disorders. $\mathrm{Br} J$ Dermatol 160 $229-232$

Smith MS, Martin-Herz SP, Womack WM, and Marsigan JL (2003) Comparative study of anxiety, depression, somatization, functional disability, and illness attribution in adolescents with chronic fatigue or migraine. Pediatrics 111:e376-e381.

Smits B, van den Heuvel L, Knoop H, Küsters B, Janssen A, Borm G, Bleijenberg G, Rodenburg R, and van Engelen B (2011) Mitochondrial enzymes discriminate between mitochondrial disorders and chronic fatigue syndrome. Mitochondrion 11 : $735-738$.
Sotzny F, Blanco J, Capelli E, Castro-Marrero J, Steiner S, Murovska M, and Scheibenbogen C; European Network on ME/CFS (EUROMENE) (2018) Myalgic encephalomyelitis/chronic fatigue syndrome-evidence for an autoimmune disease. Autoimmun Rev 17:601-609.

Suárez A, Guillamó E, Roig T, Blázquez A, Alegre J, Bermúdez J, Ventura JL, García-Quintana AM, Comella A, Segura R, et al. (2010) Nitric oxide metabolite production during exercise in chronic fatigue syndrome: a case-control study. $J$ Womens Health (Larchmt) 19:1073-1077.

Sumbalová Z, Kucharská J, and Kristek F (2010) Losartan improved respiratory function and coenzyme $Q$ content in brain mitochondria of young spontaneously hypertensive rats. Cell Mol Neurobiol 30:751-758.

Sun D, Zhuang X, Xiang X, Liu Y, Zhang S, Liu C, Barnes S, Grizzle W, Miller D, and Zhang HG (2010) A novel nanoparticle drug delivery system: the antiinflammatory activity of curcumin is enhanced when encapsulated in exosomes. Mol Ther 18:1606-1614.

Sun S, Sursal T, Adibnia Y, Zhao C, Zheng Y, Li H, Otterbein LE, Hauser CJ, and Itagaki K (2013) Mitochondrial DAMPs increase endothelial permeability through neutrophil dependent and independent pathways. PLoS One 8:e59989.

Swindle EJ and Metcalfe DD (2007) The role of reactive oxygen species and nitric oxide in mast cell-dependent inflammatory processes. Immunol Rev 217:186-205.

Taildeman J, Pérez-Novo CA, Rottiers I, Ferdinande L, Waeytens A, De Colvenaer V, Bachert C, Demetter P, Waelput W, Braet K, et al. (2009) Human mast cells express leptin and leptin receptors. Histochem Cell Biol 131:703-711.

Takeuchi K, Yamamoto K, Ohishi M, Takeshita H, Hongyo K, Kawai T, Takeda M, Kamide K, Kurtz TW, and Rakugi H (2013) Telmisartan modulates mitochondrial function in vascular smooth muscle cells. Hypertens Res 36:433-439.

Taliou A, Zintzaras E, Lykouras L, and Francis K (2013) An open-label pilot study of a formulation containing the anti-inflammatory flavonoid luteolin and its effects on behavior in children with autism spectrum disorders. Clin Ther 35:592-602.

Taracanova A, Alevizos M, Karagkouni A, Weng Z, Norwitz E, Conti P, Leeman SE, and Theoharides TC (2017) SP and IL-33 together markedly enhance TNF synthesis and secretion from human mast cells mediated by the interaction of their receptors. Proc Natl Acad Sci USA 114:E4002-E4009.

Theoharides TC (1990) Mast cells: the immune gate to the brain. Life Sci 46:607-617. Theoharides TC (2013) Atopic conditions in search of pathogenesis and therapy. Clin Ther 35:544-547.

Theoharides TC (2016) Danger signals and inflammation. Clin Ther 38:996-999.

Theoharides TC (2017) Neuroendocrinology of mast cells: challenges and controversies. Exp Dermatol 26:751-759.

Theoharides TC, Alysandratos KD, Angelidou A, Delivanis DA, Sismanopoulos N, Zhang B, Asadi S, Vasiadi M, Weng Z, Miniati A, et al. (2012) Mast cells and inflammation. Biochim Biophys Acta 1822:21-33.

Theoharides TC, Asadi S, Panagiotidou S, and Weng Z (2013) The "missing link" in autoimmunity and autism: extracellular mitochondrial components secreted from activated live mast cells. Autoimmun Rev 12:1136-1142.

Theoharides TC, Betchaku T, and Douglas WW (1981) Somatostatin-induced histamine secretion in mast cells; Characterization of the effect. Eur J Pharmacol 69(2): $127-137$.

Theoharides TC and Cochrane DE (2004) Critical role of mast cells in inflammatory diseases and the effect of acute stress. J Neuroimmunol 146:1-12.

Theoharides TC, Conti P, and Economu M (2014) Brain inflammation, neuropsychiatric disorders, and immunoendocrine effects of luteolin. J Clin Psychopharmacol 34:187-189.

Theoharides TC, Donelan JM, Papadopoulou N, Cao J, Kempuraj D, and Conti P (2004a) Mast cells as targets of corticotropin-releasing factor and related peptides. Trends Pharmacol Sci 25:563-568.

Theoharides TC and Kalogeromitros D (2006) The critical role of mast cells in allergy and inflammation. Ann N Y Acad Sci 1088:78-99.

Theoharides TC, Kempuraj D, Tagen M, Conti P, and Kalogeromitros D (2007) Differential release of mast cell mediators and the pathogenesis of inflammation. Immunol Rev 217:65-78.

Theoharides TC and Konstantinidou AD (2007) Corticotropin-releasing hormone and the blood-brain-barrier. Front Biosci 12:1615-1628.

Theoharides TC, Makris M, and Kalogeromitros D (2008) Allergic inflammation and adipocytokines. Int J Immunopathol Pharmacol 21:1-4.

Theoharides TC, Petra AI, Taracanova A, Panagiotidou S, and Conti P (2015a) Targeting IL-33 in autoimmunity and inflammation. J Pharmacol Exp Ther 354: 24-31.

Theoharides TC, Singh LK, Boucher W, Pang X, Letourneau R, Webster E, and Chrousos G (1998) Corticotropin-releasing hormone induces skin mast cell degranulation and increased vascular permeability, a possible explanation for its proinflammatory effects. Endocrinology 139:403-413.

Theoharides TC, Sismanopoulos N, Delivanis DA, Zhang B, Hatziagelaki EE, and Kalogeromitros D (2011) Mast cells squeeze the heart and stretch the gird: their role in atherosclerosis and obesity. Trends Pharmacol Sci 32:534-542.

Theoharides TC and Stewart JM (2016) Post-Lyme syndrome-associated polyneuropathy treated with immune immunoglobulin and a luteolin-containing formulation. J Clin Psychopharmacol 36:290-291.

Theoharides TC, Stewart JM, Hatziagelaki E, and Kolaitis G (2015b) Brain "fog," inflammation and obesity: key aspects of neuropsychiatric disorders improved by luteolin. Front Neurosci 9:225.

Theoharides TC, Tsilioni I, Arbetman L, Panagiotidou S, Stewart JM, Gleason RM, and Russell IJ (2015c) Fibromyalgia syndrome in need of effective treatments. $J$ Pharmacol Exp Ther 355:255-263.

Theoharides TC, Tsilioni I, Patel AB, and Doyle R (2016) Atopic diseases and inflammation of the brain in the pathogenesis of autism spectrum disorders. Transl Psychiatry 6:e844.

Theoharides TC, Valent P, and Akin C (2015d) Mast cells, mastocytosis, and related disorders. N Engl J Med 373:163-172. 
Theoharides TC, Weinkauf C, and Conti P (2004b) Brain cytokines and neuropsychiatric disorders. J Clin Psychopharmacol 24:577-581.

Theoharides TC, Zhang B, Kempuraj D, Tagen M, Vasiadi M, Angelidou A, Alysandratos KD, Kalogeromitros D, Asadi S, Stavrianeas N, et al. (2010) IL-33 augments substance P-induced VEGF secretion from human mast cells and is increased in psoriatic skin. Proc Natl Acad Sci USA 107:4448-4453.

Tomas C, Brown A, Strassheim V, Elson JL, Newton J, and Manning P (2017) Cellular bioenergetics is impaired in patients with chronic fatigue syndrome. PLoS One 12: 0186802.

Tomas C and Newton J (2018) Metabolic abnormalities in chronic fatigue syndrome/myalgic encephalomyelitis: a mini-review. Biochem Soc Trans 46: 547-553.

Toniato E, Frydas I, Robuffo I, Ronconi G, Caraffa Al, Kritas SK, and Conti P (2017) Activation and inhibition of adaptive immune response mediated by mast cells. $J$ Biol Regul Homeost Agents 31:543-548.

Trivedi MS, Oltra E, Sarria L, Rose N, Beljanski V, Fletcher MA, Klimas NG, and Nathanson L (2018) Identification of myalgic encephalomyelitis/chronic fatigue syndrome-associated DNA methylation patterns. PLoS One 13:e0201066.

Tsai AG, Wadden TA, Sarwer DB, Berkowitz RI, Womble LG, Hesson LA, Phelan S, and Rothman R (2008) Metabolic syndrome and health-related quality of life in obese individuals seeking weight reduction. Obesity (Silver Spring) 16:59-63.

Tsilioni I, Taliou A, Francis K, and Theoharides TC (2015) Children with autism spectrum disorders, who improved with a luteolin-containing dietary formulation, show reduced serum levels of TNF and IL-6. Transl Psychiatry 5:e647.

Tung HY, Plunkett B, Huang SK, and Zhou Y (2014) Murine mast cells secrete and respond to interleukin-33. J Interferon Cytokine Res 34:141-147.

Unger ER, Lin JS, Brimmer DJ, Lapp CW, Komaroff AL, Nath A, Laird S, and Iskander J (2016) CDC grand rounds: chronic fatigue syndrome-advancing research and clinical education. MMWR Morb Mortal Wkly Rep 65:1434-1438.

Valero T (2014) Mitochondrial biogenesis: pharmacological approaches. Curr Pharm Des 20:5507-5509.

Vasiadi M, Newman J, and Theoharides TC (2014) Isoflavones inhibit poly(I:C)induced serum, brain, and skin inflammatory mediators - relevance to chronic fatigue syndrome. $J$ Neuroinflammation 11:168.

Vermeulen RC, Kurk RM, Visser FC, Sluiter W, and Scholte HR (2010) Patients with chronic fatigue syndrome performed worse than controls in a controlled repeated exercise study despite a normal oxidative phosphorylation capacity. J Transl Med 8:93.

Vermeulen RC and Vermeulen van Eck IW (2014) Decreased oxygen extraction during cardiopulmonary exercise test in patients with chronic fatigue syndrome. $J$ Transl Med 12:20.

Vij G, Gupta A, and Chopra K (2009) Modulation of antigen-induced chronic fatigue in mouse model of water immersion stress by naringin, a polyphenolic antioxidant. Fundam Clin Pharmacol 23:331-337.

Vincent A, Brimmer DJ, Whipple MO, Jones JF, Boneva R, Lahr BD, Maloney E, St Sauver JL, and Reeves WC (2012) Prevalence, incidence, and classification of chronic fatigue syndrome in Olmsted County, Minnesota, as estimated using the Rochester Epidemiology Project. Mayo Clin Proc 87:1145-1152.

Wang G, Pierangeli SS, Papalardo E, Ansari GA, and Khan MF (2010) Markers of oxidative and nitrosative stress in systemic lupus erythematosus: correlation with disease activity. Arthritis Rheum 62:2064-2072.
Weng Z, Patel AB, Panagiotidou S, and Theoharides TC (2015) The novel flavone tetramethoxyluteolin is a potent inhibitor of human mast cells. J Allergy Clin Immunol 135:1044-1052.e5.

Wernersson S and Pejler G (2014) Mast cell secretory granules: armed for battle. Nat Rev Immunol 14:478-494.

Whitmore KE and Theoharides TC (2011) When to suspect interstitial cystitis. J Fam Pract 60:340-348.

Wyller VB, Barbieri R, and Saul JP (2011) Blood pressure variability and closed-loop baroreflex assessment in adolescent chronic fatigue syndrome during supine rest and orthostatic stress. Eur J Appl Physiol 111:497-507.

Wyller VB, Saul JP, Walløe L, and Thaulow E (2008) Sympathetic cardiovascular control during orthostatic stress and isometric exercise in adolescent chronic fatigue syndrome. Eur J Appl Physiol 102:623-632.

Xiao ZP, Peng ZY, Peng MJ, Yan WB, Ouyang YZ, and Zhu HL (2011) Flavonoids health benefits and their molecular mechanism. Mini Rev Med Chem 11:169-177.

$\mathrm{Xu} \mathrm{H}$, Bin NR, and Sugita S (2018) Diverse exocytic pathways for mast cell mediators. Biochem Soc Trans 46:235-247.

Xu M, Dai W, and Deng X (2002) Effects of magnesium sulfate on brain mitochondrial respiratory function in rats after experimental traumatic brain injury. Chin $J$ Traumatol 5:361-364.

Yamano E, Sugimoto M, Hirayama A, Kume S, Yamato M, Jin G, Tajima S, Goda N, Iwai K, Fukuda S, et al. (2016) Index markers of chronic fatigue syndrome with dysfunction of TCA and urea cycles. Sci Rep 6:34990.

Yancey JR and Thomas SM (2012) Chronic fatigue syndrome: diagnosis and treatment. Am Fam Physician 86:741-746.

Yang TY, Kuo HT, Chen HJ, Chen CS, Lin WM, Tsai SY, Kuo CN, and Kao CH (2015) Increased risk of chronic fatigue syndrome following atopy: a population-based study. Medicine (Baltimore) 94:e1211.

Yang X, Zhu J, and Tang Z (2007) Interventional effect of magnesium sulfate on nitric oxide synthase activity after acute craniocerebral injury. Neural Regen Res 2:251-253.

Zhang B, Alysandratos KD, Angelidou A, Asadi S, Sismanopoulos N, Delivanis DA, Weng Z, Miniati A, Vasiadi M, Katsarou-Katsari A, et al. (2011) Human mast cell degranulation and preformed TNF secretion require mitochondrial translocation to exocytosis sites: relevance to atopic dermatitis. J Allergy Clin Immunol 127: 1522-1531.e8.

Zhang B, Angelidou A, Alysandratos KD, Vasiadi M, Francis K, Asadi S, Theoharides A, Sideri K, Lykouras L, Kalogeromitros D, et al. (2010) Mitochondrial DNA and antimitochondrial antibodies in serum of autistic children. $J$ Neuroinflammation 7:80.

Zhang B, Asadi S, Weng Z, Sismanopoulos N, and Theoharides TC (2012) Stimulated human mast cells secrete mitochondrial components that have autocrine and paracrine inflammatory actions. PLoS One 7:e49767.

Zhang X, Wang Y, Dong H, Xu Y, and Zhang S (2016) Induction of microglial activation by mediators released from mast cells. Cell Physiol Biochem 38:1520-1531.

Zhang Y, Xun P, Wang R, Mao L, and He K (2017) Can magnesium enhance exercise performance? Nutrients 9:E946.

Address correspondence to: Dr. Theoharis C. Theoharides, Department of Immunology, Tufts University School of Medicine, 136 Harrison Avenue, Suite J304, Boston, MA 02111. E-mail: theoharis.theoharides@tufts.edu 